\title{
Imperfect Credibility and the Zero Lower Bound on the Nominal Interest Rate*
}

\author{
Martin Bodenstein, James Hebden, and Ricardo Nunes** \\ Federal Reserve Board
}

First version: April 2010

This version: August 2010

\begin{abstract}
When the nominal interest rate reaches its zero lower bound, credibility is crucial for conducting forward guidance. We determine optimal policy in a New Keynesian model when the central bank has imperfect credibility and cannot set the nominal interest rate below zero. In our model, an announcement of a low interest rate for an extended period does not necessarily reflect high credibility. Even if the central bank does not face a temptation to act discretionarily in the current period, policy commitments should not be postponed. Nevertheless, even banks with low credibility should use forward guidance to the best of their abilities. In reality, central banks are often reluctant to allow a recovery path with output and inflation temporarily above target. From the perspective of our model such a policy reflects a low degree of credibility. We find increased forecast uncertainty in inflation and the output gap at the zero lower bound while interest rate uncertainty is reduced. This change in uncertainty is more pronounced for policymakers with less credibility. Furthermore, misalignments between announced interest rate paths and market expectations are found to be best explained by lack of credibility.
\end{abstract}

Keywords: monetary policy, zero interest rate bound, commitment, liquidity trap

JEL Classification: C61, E31, E52

* We are grateful to David Kjellberg and Lars Svensson for sharing their data. We are also grateful to Gauti Eggertsson, Tack Yun and seminar participants at the Federal Reserve Board, Georgetown University, 2010 NBER Summer Institute (Monetary Economics), Swiss National Bank, and 2010 Computing in Economics and Finance Meeting for helpful comments. The views expressed in this paper are solely the responsibility of the authors and should not be interpreted as reflecting the views of the Board of Governors of the Federal Reserve System or of any other person associated with the Federal Reserve System.

** Contact information: Martin Bodenstein: phone (202) 452 3796, Martin.R.Bodenstein@frb.gov; James Hebden: phone (202) 452 3159, James.S.Hebden@frb.gov; Ricardo Nunes: phone (202) 452 2337, Ricardo.P.Nunes@frb.gov. 


\section{Introduction}

When the nominal interest rate reaches zero, the central bank faces a time inconsistency problem. Initially, a promise to keep the nominal interest rate low for an extended period will raise inflation expectations, lower current and future real interest rates, and thus stimulate current output. However, once the economy has emerged from the recession, honoring the earlier promise of low interest rates overstimulates the economy leading to elevated inflation and a positive output gap. Therefore, a central bank whose announced promises for the interest rate path are perceived as not credible cannot provide effective forward guidance and the economy goes through a deeper recession than otherwise. Whereas commitment always matters for the conduct of monetary policy, its importance is even higher at the zero lower bound as low credibility cannot be compensated for by movements in the contemporaneous interest rate. ${ }^{1}$

Academics and policymakers alike deem central bank credibility pivotal for the conduct of monetary policy as documented in Blinder (2000). However, recent episodes of zero (or very low) interest rates suggest that the credibility of central banks in industrialized economies is imperfect. For example in 1999/2000, the Bank of Japan never followed the prescription of the optimal policy under full commitment. After instituting a zero interest rate policy in February 1999, it raised interest rates in March 2000 although the economy was still weak and inflation was negative.

We analyze the optimal monetary policy in a standard New Keynesian model when the central bank has imperfect credibility and the nominal interest rate is constrained to be nonnegative. The central bank can promise a policy plan; however, in the future it may obtain the opportunity to discard its earlier promises and re-optimize. This framework captures the fact that in practice central banks do not operate under full commitment or full discretion but have an intermediate degree of credibility. Furthermore, our modeling strategy allows us to address the following questions. How does the possibility of future renouncements influence current

\footnotetext{
${ }^{1}$ Following the seminal papers by Kydland and Prescott (1977) and Barro and Gordon (1983) the literature has taken two different approaches to tackle optimal policy problems - commitment and no commitment. Eggertsson (2006) discusses in detail the time inconsistency problem associated with the zero lower bound constraint.
} 
policies and promises? What are the economic consequences of policy renouncements? How does the temptation to default evolve over time?

First, as private agents' expectations reflect the possibility of future policy renouncements under imperfect credibility, the central bank resorts to an even more extreme promise about keeping the interest rate at zero than under full commitment. Hence, the mere announcement to keep the interest rate low for an extended period is not necessarily a sign of credibility. Second, re-optimization does not prompt an immediate exit from the zero bound unless the economy has sufficiently recovered. However, the new policy promises to raise the interest rate earlier in order to moderate the post-recession boom. And third, policy renouncements are most valuable when the economy is about to emerge from the zero lower bound regime. At this stage, the benefits from forward guidance have been reaped whereas the welfare costs of elevated inflation and higher output gap have not yet materialized.

Our results support the view expressed in Walsh (2009) that central banks operate under imperfect commitment and have not followed the prescriptions of the optimal monetary policy under full commitment as derived in the New Keynesian model. Federal Reserve officials have stated publicly that promising to keep both inflation and the output gap above target is currently not considered, i.e., they do not intend to follow the optimal policy prescription of the New Keynesian model. While there may be other interpretations of such statements, our model establishes a theoretical link to central bank credibility and suggests that it is low.

Furthermore, when the Swedish Riksbank lowered its path for the repo-rate in April 2009, market expectations decoupled from the announced repo-rate path, thus raising doubts about the credibility of the Riksbank - see Svensson $(2009,2010)$. Through the lens of our model, such misalignments between the announced interest rate path and market expectations more likely stem from imperfect credibility rather than increased forecast uncertainty. Whereas uncertainty about inflation and the output gap rises, the forecast for the interest rate becomes less uncertain at the zero bound. Our model also provides insight why central banks, in particular the Federal Reserve System, have come under unprecedented political pressure in the aftermath of the 2008 financial crisis. Even without changes in the political environment, the temptation to 
re-optimize a policy path is substantially larger in a recession with the interest rate at zero than in more stable economic times.

Our work is related to Adam and Billi (2006, 2007) and Nakov (2008) who analyze stochastic economies imposing the zero lower bound as an occasionally binding constraint. These authors focus on the extreme cases of full commitment and full discretion. Schaumburg and Tambalotti (2007) examine imperfect commitment but abstract from the zero lower bound. ${ }^{2}$ Since the zero lower bound introduces pronounced non-linearities, closed form solutions as described in Schaumburg and Tambalotti (2007) are not available. Instead, we use the imperfect credibility setting with global methods proposed in Debortoli and Nunes (2010).

Eggertsson and Woodford (2003) suggest that the optimal monetary policy at the zero lower bound can be implemented through targeting an output-gap adjusted price index. Communicating the optimal policy through a path for the price level rather than the interest rate might be preferred as such a communication approach is more transparent. However, as Gertler (2003) points out in his discussion of Eggertsson and Woodford (2003), for this communication strategy to be successful, the policymaker would need to be able to commit to a price level targeting rule that she would like to renege on in every period. Thus, the concerns derived from our framework of limited credibility still apply.

Benhabib et al. $(2001,2002)$ show that once the zero lower bound on the nominal interest rate is taken into account, active interest rate feedback rules can lead to liquidity traps and multiple equilibria. Schmitt-Grohé and Uribe (2007) follow a different strategy by analyzing simple rules in stochastic economies and checking ex-post that the zero lower bound constraint is not violated too often. In this paper, we do not focus on interest rate rules nor on multiple equilibria.

Other authors opted to examine the implications of the zero lower bound constraint in settings akin to perfect foresight, e.g., Eggertsson and Woodford (2003), Jung et al. (2005), Levin et al. (2009) and Bodenstein et al. (2009). This modeling approach allows for analyzing more complex models. However, under perfect foresight agents do not take into account the possi-

\footnotetext{
${ }^{2}$ The imperfect commitment setting with stochastic replanning was first proposed in Roberds (1987). Ball (1995) examines the role of imperfect credibility in disinflation episodes.
} 
bility of future shocks when forming their expectations. In our setting of imperfect credibility, the uncertainty about future shocks and the possibility of policy renouncements crucially shape agents' expectations and impact the policy plans of the central bank. Thus, global methods that can handle occasionally binding constraints need to be employed.

The remainder of this paper is organized as follows. Section 2 presents our modeling framework. In Section 3 we report results derived from our model. Using suggestive evidence, Section 4 discusses the credibility of some central banks in light of our results. Sensitivity analysis is offered in Section 5, before we conclude in Section 6.

\section{The Model}

The model consists of two building blocks: the private sector and the monetary authority. The behavior of the private sector is given by a standard New Keneysian model as described among others in Yun (1996), Clarida et al. (1999), and Woodford (2003). The central bank attempts to maximize the welfare of the representative household, but faces two limitations. First, the central bank's single tool is the nominal interest rate on one-period, non-contingent debt which cannot fall below zero (zero lower bound). Second, the central bank's commitment to earlier plans is revoked with a known and fixed probability (imperfect credibility).

\subsection{Private Sector}

The optimization problems of households and firms imply the well-known linear aggregate demand and supply relationships

$$
\begin{aligned}
& \pi_{t}=\kappa y_{t}+\beta E_{t} \pi_{t+1}+u_{t} \\
& y_{t}=E_{t} y_{t+1}-\sigma\left(i_{t}-E_{t} \pi_{t+1}\right)+g_{t},
\end{aligned}
$$

where $u_{t}$ is a cost push shock

$$
u_{t}=\rho_{u} u_{t-1}+\varepsilon_{u, t},
$$

and $g_{t}$ is a demand shock

$$
g_{t}=\rho_{g} g_{t-1}+\varepsilon_{g, t} .
$$


$\pi_{t}$ denotes the inflation rate, $y_{t}$ is the output gap, and $i_{t}$ is the nominal interest rate on one period non-contingent debt. ${ }^{3}$ Policymakers do not tax money holdings and thus the nominal interest rate is bounded from below. ${ }^{4}$ As $i_{t}$ is expressed in deviation from the steady state interest rate (with zero steady state inflation), this condition reads as follows

$$
i_{t} \geq-r^{*}
$$

where $r^{*}$ is the value of the nominal interest rate in steady state. For later use, we also define the level of the nominal interest rate $\tilde{i}_{t} \equiv i_{t}+r^{*}$.

The discount factor is denoted by $\beta \in(0,1)$ and the slope of the Phillips curve is $\kappa=$ $\frac{(1-v)(1-v \beta)}{v} \frac{\sigma^{-1}+\omega}{1+\omega \theta} . \quad v$ is the probability with which a firm cannot adjust its price, $\sigma$ is the intertemporal elasticity of substitution of the household, $\omega$ measures the elasticity of a firm's real marginal cost with respect to its own output level, and $\theta$ is the elasticity of substitution between the varieties produced by the monopolistic competitors.

\subsection{Monetary Policy}

The monetary authority minimizes the present discounted value of its period objective function subject to the constraints (1) - (5) using the one-period nominal interest rate as its policy instrument. The period utility function $U_{t}$ is of the quadratic form

$$
U_{t}=-\pi_{t}^{2}-\lambda y_{t}^{2}
$$

\footnotetext{
${ }^{3}$ The representative household in this economy chooses consumption, leisure, money and bond holdings subject to her budget constraint. Firms are monopolistic competitors and set nominal prices. The nominal price contracts are modeled as in Calvo (1983) and Yun (1996), i.e., each period only a fixed fraction of firms is allowed to re-optimize prices. We follow the literature in using the linear equations that are obtained from loglinearizing the nonlinear equations around the model's deterministic steady state. Although such an approach removes possibly interesting nonlinearities, it facilitates our computations and the comparisons with earlier work on the zero bound constraint and/or optimal monetary policy. See also the discussion in Section 2.1 in Adam and Billi (2006).

${ }^{4}$ Goodfriend (2000) proposes three options to overcome the zero bound on interest rate policy: a carry tax on money, open market operations in long bonds, and monetary transfers. Our choice to not include into our analysis these and other policies, such as fiscal stimulus (Christiano et al. (2009), Eggertsson (2010), Erceg and Lindé (2010)) and credit easing policies (Gertler and Karadi (2009), Del Negro et al. (2009)), should not be interpreted as us passing judgement on the effectiveness of these policies. Furthermore, recent public debate in the U.S. indicates that political limits apply to employing these policies. The purpose of our paper is to shed light on the effectiveness of forward guidance through short term interest rates.
} 
Following the derivations in Woodford (2003), we assume $\lambda=\frac{\kappa}{\theta}$.

As in Roberds (1987), Schaumburg and Tambalotti (2007), and Debortoli and Nunes (2010), the policymaker has imperfect credibility. At the beginning of each time period, a realization of the random variable $X$ is drawn with $X=\{C, D\}$ and the probability distribution

$$
p(x)=\left\{\begin{array}{cc}
\eta & \text { if } x=C \\
1-\eta & \text { if } x=D
\end{array}\right.
$$

with $\eta \in[0,1]$. In the event $x=C$, the policymaker follows her previously announced policy path, whereas she reneges on her earlier promises if $x=D$. Thus, a policymaker's promises made in time $t$ about the future path of the nominal interest rate will be implemented in period $t+s$ with probability $\eta^{s}$.

If $\eta=1$, policy promises are always kept and the policymaker is referred to as fully committed or perfectly credible. If $\eta=0$, the policymaker acts under full discretion. Adam and Billi (2006, 2007) analyze the optimal monetary policy under the zero bound constraint in a fully stochastic environment for these two cases. ${ }^{5}$ The cases with $\eta \in[0,1]$ have not been previously analyzed and correspond to imperfect credibility where policy renouncements occur.

Assuming the default events to be stochastic rather than endogenous decision is a simplification analogous to the Calvo pricing model. This approach seems justified if some defaults are uncorrelated with the state of the economy. Possible candidates for such events are changes in the dominating view within a central bank due to time-varying composition of its decisionmaking committee or varying intensity of outside pressures by politicians and the financial industry. ${ }^{6}$ Alternatively, our approach can be interpreted as reduced form of a model in which a policymaker's announcements are credible only to the extent that it is in her interest to fulfill these announcements given a threat of punishment for defaulting. If imposing the punishment

\footnotetext{
${ }^{5}$ Nakov (2008) performs a similar analysis but includes instrument and targeting rules.

${ }^{6}$ In the case of the United States, the reserve bank presidents serve one-year terms as voting members of the FOMC on a rotating basis, except for the president of the New York Fed. Furthermore, substantial turnover among the reserve bank presidents and the members of the Board of Governors arises due to retirement and outside options. With the (up to) seven members of the Board of Governors being nominated by the U.S. President and confirmed by the U.S. Senate, the composition of views in the FOMC may be affected by the views of the political party in power at the time of the appointment. Chappell et al. (1993) and Berger and Woitek (2005) find evidence of such effects in the US and Germany, respectively.
} 
for default requires coordination among private agents, and this coordination process breaks down randomly, such a model may bear similarities with our approach. ${ }^{7}$

Whereas our approach cannot explain the timing of a default, it allows us to examine the interaction between the anticipation of future policy re-optimizations and commitments, and to analyze the effects of policy renouncements and the welfare effects of doing so. These issues cannot be addressed in either the full commitment or the discretion framework. While more complex credibility settings that could also explain the timing of defaults are easily imagined, they come at greater computational burden.

Under imperfect credibility, the optimization problem of the policymaker is stated as

$$
\begin{aligned}
V\left(u_{t}, g_{t}\right) & =\max _{\left\{y_{t}, \pi_{t}, i_{t}\right\}} E_{t} \sum_{t=0}^{\infty}(\beta \eta)^{t}\left\{-\pi_{t}^{2}-\lambda y_{t}^{2}+\beta(1-\eta) E_{t} V^{D}\left(u_{t+1}, g_{t+1}\right)\right\} \\
\text { s.t. } \pi_{t} & =\kappa y_{t}+\beta \eta E_{t} \pi_{t+1}+\beta(1-\eta) E_{t} \pi_{t+1}^{D}+u_{t} \\
y_{t} & =\eta E_{t} y_{t+1}+(1-\eta) E_{t} y_{t+1}^{D}-\sigma\left(i_{t}-\eta E_{t} \pi_{t+1}-(1-\eta) E_{t} \pi_{t+1}^{D}\right)+g_{t} \\
i_{t} & \geq-r^{*} \\
u_{t} & =\rho_{u} u_{t-1}+\varepsilon_{u, t} \\
g_{t} & =\rho_{g} g_{t-1}+\varepsilon_{g, t},
\end{aligned}
$$

where variables evaluated under default carry the superscript D.

The objective function contains two parts. The first term in the summation refers to future paths in which current promises are kept. The possibility of future re-optimizations causes such histories to be discounted at the rate $\beta \eta$. Second, at any point in time, current promises are discarded with probability $1-\eta$ and a new policy is formulated. The value obtained by the monetary authority in that case is summarized in the function $V^{D}$. The expectation terms in the constraints also reflect the uncertainty about future policy renouncements.

\footnotetext{
${ }^{7}$ Such a framework would build on the seminal contributions of Chari and Kehoe (1990), and Kehoe and Levine (1993). A related approach using a model of imperfect information is described in Sleet (2001).
} 


\subsection{Equilibrium and Solution}

Recasting problem 7 into the recursive formulation of Marcet and Marimon (2009) and rearranging terms, the problem can be written as

$$
\begin{aligned}
V\left(u_{t}, g_{t}, \mu_{t}^{1}, \mu_{t}^{2}\right) & =\min _{\left\{\gamma_{t}^{1}, \gamma_{t}^{2}\right\}} \max _{\left\{y_{t}, \pi_{t}, i_{t}\right\}} h\left(y_{t}, \pi_{t}, i_{t}, \gamma_{t}^{1}, \gamma_{t}^{2}, \mu_{t}^{1}, \mu_{t}^{2}, u_{t}, g_{t}\right) \\
& +\beta \eta E_{t} V\left(u_{t+1}, g_{t+1}, \mu_{t+1}^{1}, \mu_{t+1}^{2}\right) \\
& +\beta(1-\eta) E_{t} V^{D}\left(u_{t+1}, g_{t+1}\right) \\
\text { s.t. } i_{t} & \geq-r^{*} \\
u_{t} & =\rho_{u} u_{t-1}+\varepsilon_{u, t} \\
g_{t} & =\rho_{g} g_{t-1}+\varepsilon_{g, t} \\
\mu_{t+1}^{1} & =\gamma_{t}^{1}, \mu_{0}^{1}=0 \\
\mu_{t+1}^{2} & =\gamma_{t}^{2}, \mu_{0}^{2}=0
\end{aligned}
$$

where $\left(\gamma_{t}^{1}, \gamma_{t}^{2}\right)$ are the Lagrange multipliers associated with the aggregate supply and demand constraints,

$$
\begin{aligned}
h\left(y_{t}, \pi_{t}, i_{t}, \gamma_{t}^{1}, \gamma_{t}^{2}, \mu_{t}^{1}, \mu_{t}^{2}, u_{t}, g_{t}\right) \equiv & -\pi_{t}^{2}-\lambda y_{t}^{2} \\
& +\gamma_{t}^{1}\left(\pi_{t}-\kappa y_{t}-\beta(1-\eta) E_{t} \pi_{t+1}^{D}-u_{t}\right) \\
& \left.+\gamma_{t}^{2}\left(-y_{t}+(1-\eta) E_{t} y_{t+1}^{D}-\sigma\left(i_{t}-(1-\eta) E_{t} \pi_{t+1}^{D}\right)+g_{t}\right)\right\} \\
& -I_{\eta} \mu_{t}^{1} \pi_{t}+I_{\eta} \frac{1}{\beta} \mu_{t}^{2}\left(y_{t}+\sigma \pi_{t}\right)
\end{aligned}
$$

and $I_{\eta}$ is an indicator function satisfying

$$
I_{\eta}=\left\{\begin{array}{cc}
0 & \text { if } \eta=0 \\
1 & \text { if } \eta \neq 0
\end{array}\right.
$$

It follows from Marcet and Marimon (2009) and Debortoli and Nunes (2010) that the optimal policy and the value functions are time invariant if the state space is enlarged to contain the lagged Lagrange multipliers $\left(\mu_{t}^{1}, \mu_{t}^{2}\right)$. The multipliers summarize previous state contingent promises, with the case of non-binding promises corresponding to the multipliers 
being zero. ${ }^{8}$ Since the multipliers are not physical state variables, only commitment impedes the monetary authority from ignoring previous promises, reflecting the time inconsistent nature of the problem. In fact, resetting the Lagrange multipliers to zero is optimal, and occurs in equilibrium when the monetary authority is allowed to do so. Definition 1 specifies the equilibrium concept.

Definition 1 The equilibrium with imperfect commitment satisfies the following conditions:

1. Given $\left\{y_{t}^{D}, \pi_{t}^{D}\right\}_{t=0}^{\infty}$ and the value $V^{D}$, the path $\left\{y_{t}, \pi_{t}, i_{t}\right\}_{t=0}^{\infty}$ solves problem (7).

2. The value function $V^{D}$ is such that $V^{D}\left(u_{t}, g_{t}\right)=V\left(u_{t}, g_{t}, \mu_{t}^{1}=0, \mu_{t}^{2}=0\right)$ and $V$ is defined by equation (8).

3. Denote the optimal policy functions as $\left(y_{t}, \pi_{t}\right)=\psi\left(u_{t}, g_{t}, \mu_{t}^{1}, \mu_{t}^{2}\right)$. The pair $\left(y_{t}^{D}, \pi_{t}^{D}\right)$ satisfies the condition $\left(y_{t}^{D}, \pi_{t}^{D}\right)=\psi\left(u_{t}, g_{t}, 0,0\right)$.

First, the definition requires optimality given the constraints. The second part defines the value of default $V^{D}$ to be the continuation value without binding promises, i.e., the lagged Lagrange multipliers are at zero. The two value functions would not coincide if policy objectives are not consensual. ${ }^{9}$ The third part requires the policy functions that private agents expect to be implemented under default $\left(y_{t}^{D}, \pi_{t}^{D}\right)$ to be consistent with the optimal policy functions implemented when there are no promises to be honored.

The solution of equation (8) is not standard, as both the value function $V^{D}$ and the policy functions under default are unknown. In addition, the solution requires maximizing with respect to the controls and minimizing with respect to the Lagrange multipliers. In the numerical algorithm described in Appendix A.2, we approximate the value function directly. As in Debortoli and Nunes (2010), we make use of Definition 1 to employ a numerical procedure with one fixed point only.

The two model features that dictate the use of global methods are the presence of the occasionally binding zero bound constraint and the possibility of policy renouncements. Most

\footnotetext{
${ }^{8}$ In the case of full discretion, the lagged Lagrange multipliers are neither zero nor a state variable. This case is covered in the general formulation by the inclusion of the indicator function $I_{\eta}$ in equation (9).

${ }^{9}$ This case is analyzed in Debortoli and Nunes (2006) who consider two political parties with different utility functions. In such a situation, the continuation value function depends on which party gains power.
} 
of the literature on monetary policy at the zero bound assumes perfect foresight. Whereas this approach allows for a simplified treatment of the binding constraint, it inhibits studying the link between monetary policy and household expectations about future policy renouncements. By construction, households do not anticipate policy changes under perfect foresight.

\section{Results}

The parameterization of our model is summarized in Table 1. To facilitate comparison with the work of Adam and Billi (2006, 2007) and Woodford (2003), we opted not to deviate from these authors' parameter choices. The one parameter in our analysis for which there is almost no guidance provided in the literature is $\eta$, the probability with which the policymaker will honor her previous promises. One can also measure the credibility level by the expected time before a policy renouncement occurs $\alpha=1 /(1-\eta)$. Throughout our discussion, we show results for the cases described in Table 2. Our analysis in Section 4 sheds some light on how to determine $\alpha$ for different central banks.

Table 1: Parameterization

\begin{tabular}{cll} 
parameter & value & economic meaning \\
\hline \hline$\beta$ & 0.9913 & discount factor \\
$v$ & 0.66 & prob. of no price change \\
$\sigma$ & 6.25 & interest rate sensitivity consumption \\
$\omega$ & 0.47 & elasticity of firms' marginal cost \\
$\theta$ & 7.66 & price elasticity of demand \\
$\kappa$ & 0.024 & slope of Phillips curve \\
$\lambda$ & 0.003 & weight on output in utility function \\
$\rho_{u}$ & 0 & persistence cost push shock \\
$\sigma_{u}$ & 0.154 & std. cost push shock \\
$\rho_{g}$ & 0.8 & persistence demand shock \\
$\sigma_{g}$ & 1.524 & std. demand shock \\
\hline
\end{tabular}

Depending on the long-run inflation target, previous research suggests that the nominal interest rate reaches the zero bound with low probability. ${ }^{10}$ However, once the economy is at

\footnotetext{
${ }^{10}$ See Reifschneider and Williams (2000), Schmitt-Grohé and Uribe (2007), Billi (2009), and most recently Williams (2010).
} 
the zero bound, as currently is the case for several industrialized countries, additional shocks have amplified consequences on economic activity. In the New Keynesian model, demand shocks are considered to be more volatile and persistent than cost-push shocks and therefore play a more important role when focusing on the zero lower bound. ${ }^{11}$ Furthermore, for a large demand shock that pushes the interest rate to zero, the economy experiences key characteristics of a liquidity trap with both output and inflation dropping. By contrast, for a cost-push shock to lower the interest rate, inflation drops but output rises.

Table 2: Imperfect credibility cases

\begin{tabular}{ccl}
$p(x=C)=\eta$ & $\alpha=\frac{1}{1-\eta}$ & economic meaning \\
\hline \hline 0 & 1 & full discretion \\
0.5 & 2 & loose commitment \\
0.75 & 4 & loose commitment \\
1 & $\infty$ & full commitment \\
\hline
\end{tabular}

\subsection{Credibility and cost-push shocks}

To illustrate the effects of imperfect credibility in a simple example, we first examine the familiar response of the economy to a cost-push shock. Figure 1 plots the responses of the nominal interest rate in levels $\tilde{i}_{t}$, the output gap $y_{t}$, and the inflation rate $\pi_{t}$ to a negative i.i.d. cost push shock (i.e., $u_{1}=-\sigma_{u}, g_{1}=0$, and $\left(\varepsilon_{u, t}, \varepsilon_{g, t}\right)=0 \forall t \geq 2$ ). Under full discretion, the economy experiences price deflation and an expansion in output. In the second period, the cost-push shock vanishes and inflation and output are back to target. ${ }^{12}$ This is not the case with full commitment. The monetary authority promises to keep the interest rate below its long-run value, thus causing persistent inflation and elevated output. Consequently, the initial impact of the shock is dampened.

\footnotetext{
${ }^{11}$ In our framework, small aggregate demand shocks can be completely offset by adjusting the nominal interest rate, as long as the interest rate is sufficiently positive.

${ }^{12} \mathrm{As}$ we solve for the model using global methods rather than linear methods, the long-run responses under full discretion do not return to zero in the presence of an occasionally binding constraint due to precautionary motives. For the case of full commitment the responses converge to nearly zero as is the case in Adam and Billi (2006).
} 
Figure 1: Cost-push Shock under Imperfect Credibility
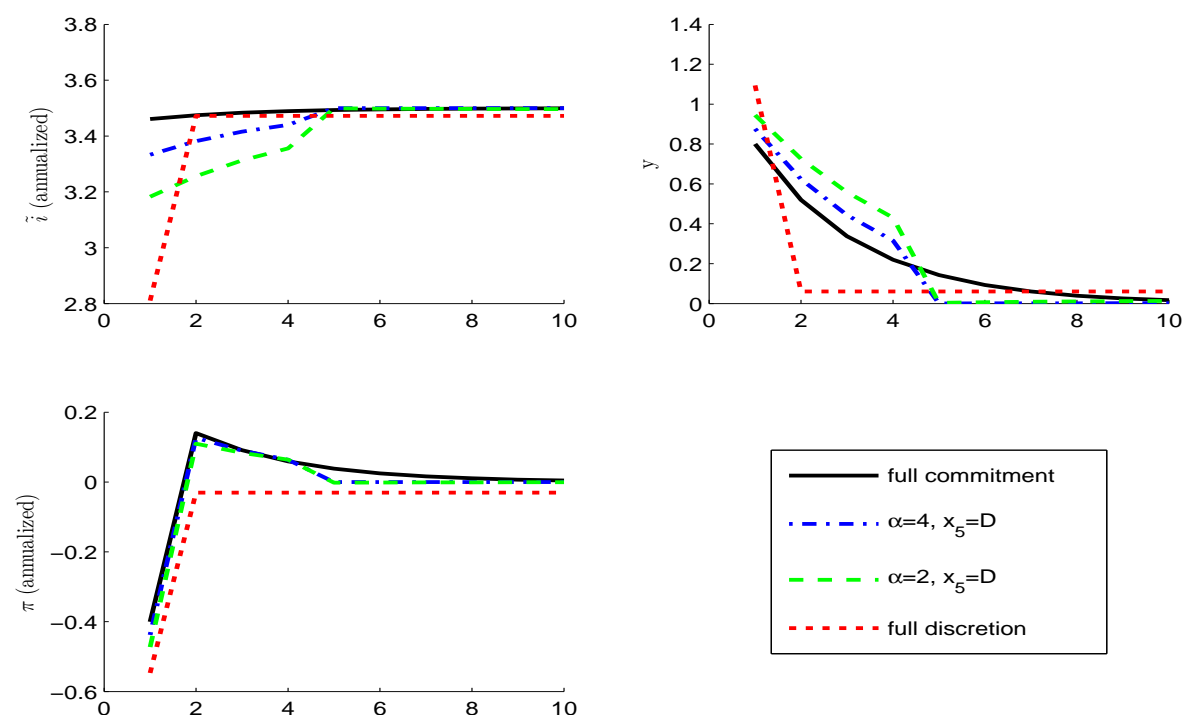

Notes: the figure plots the response to a negative cost-push shock. The shocks are initialized at $\varepsilon_{u, 1}=-\sigma_{u}, \varepsilon_{g, 1}=0$, and $\left(\varepsilon_{u, t}, \varepsilon_{g, t}\right)=0 \forall t \geq 2$. For the imperfect commitment cases $(\alpha=2$ and $\alpha=4)$, the figure plots the specific history with $x_{5}=D, x_{t}=C \forall t \neq 5$.

For the imperfect credibility settings with $\alpha=2$ and $\alpha=4$, Figure 1 considers the specific history in which the monetary authority reneges in period 5 only $\left(x_{5}=D, x_{t}=C \forall t \neq 5\right)$. Until period 4, the output gap and inflation are kept above target, honoring the monetary authority's past promises. In period 5, policy is re-optimized and it is feasible to bring output and inflation back to target. Since private agents are aware of the possibility of such future policy renouncements, the task of the central bank is adversely affected: in the first period the central bank does not stabilize the economy as effectively as under full commitment.

\subsection{Credibility at the zero lower bound}

When the nominal interest rate reaches zero in response to a large contractionary demand shock, monetary policy faces a dilemma. To mitigate the impact of the shock the central bank has to promise to keep the interest rate low for an extended period in order to allow inflation and the output gap to rise above their target values in the future. However, once the economy enters the phase of elevated inflation and a positive output gap, the central bank faces the 
temptation to renege on its earlier promise and to raise the interest rate. Under imperfect credibility, the monetary authority will not deliver on its earlier promises and will raise the interest rate path if it obtains the chance to do so. Thus, the ability of such a central bank to ease the recession may be greatly diminished.

To illustrate how policy promises and renouncements chosen under limited credibility affect the path of the economy, we analyze the impulse response functions after a large and persistent contraction in aggregate demand that pushes the nominal interest rate to zero. More specifically, across experiments we set $g_{1}=-10, u_{1}=0$, and $\left(\varepsilon_{u, t}, \varepsilon_{g, t}\right)=0 \forall t \geq 2 .{ }^{13}$ However, we consider different specific histories of $x_{t}$. Initially, the lagged Lagrange multipliers are at zero, i.e., $\mu_{1}^{1}=\mu_{1}^{2}=0$. We will consider all possible shock histories later in this section.

\subsubsection{Promises}

If the central bank has limited credibility, private agents correctly incorporate the possibility of future re-optimizations when forming expectations. The monetary authority tries to influence the expectations of the private sector by adjusting its announced policy. Figure 2 plots the optimal plan announced by the central bank without policy renouncements $\left(x_{t}=C \forall t \geq\right.$ 1) for different levels of credibility ( $\alpha=2, \alpha=4$, and full commitment). The lower the credibility of the monetary authority is, the more extreme its promises are. The policymaker with $\alpha=2$ promises to keep the interest rate at zero over the entire horizon plotted, whereas the policymaker with $\alpha=4$ promises to keep the interest rate at zero for 6 periods. Hence, the announcement that the interest rate is planned to be at zero for a long period should not be necessarily understood as a signal of high credibility. In a purely forward looking model, such inference is correct only when comparing the extreme cases of full commitment and discretion. ${ }^{14}$

However, the central bank may have to deliver on its promises. At the optimum, the policymaker equates the expected benefits from a promise to keep the interest rate low with

\footnotetext{
${ }^{13}$ The value of $g_{1}=-10$ corresponds to four times the standard deviation of $g$. While the interest rate reaches zero only in response to unusually large shocks, recently the inability to lower the interest rate below zero has had dramatic effects in several countries.

${ }^{14}$ As shown in Section 5, the observed interest rate may be lower under full discretion than under full commitment for a given demand shock if inflation is not purely forward looking due to price indexation.
} 
Figure 2: Imperfect Credibility and the Zero Lower Bound - Extreme Promises
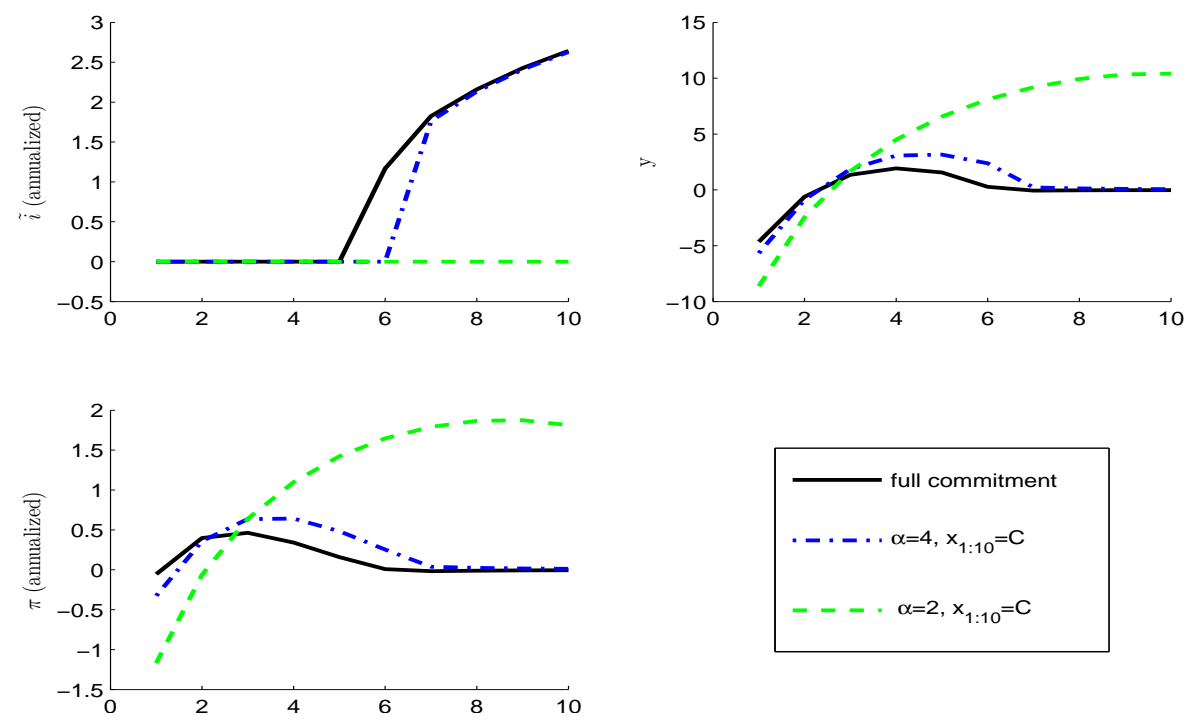

Notes: the figure plots the transition dynamics in response to a negative and large demand shock causing the interest rate to reach its zero lower bound. The shocks are initialized at $u_{1}=0, g_{1}=-10$, and $\left(\varepsilon_{u, t}, \varepsilon_{g, t}\right)=0 \forall t \geq 2$. For the imperfect commitment cases $(\alpha=2$ and $\alpha=4)$, the figure plots the specific history with $x_{t}=C$ $\forall t \geq 1$.

the expected costs of having to deliver on these promises (the cost of not defaulting). If a policymaker does not get a chance to revisit an extreme promise, the low interest rate fuels a sizable and persistent boom with increased inflation, as seen in particular for the case of $\alpha=2$.

\subsubsection{Renouncements}

While a policymaker in default ignores all past promises, the new policies depend on the state of the economy at the time of re-optimization. If the economy is still sufficiently deep in recession, the central bank will keep the interest rate at zero under its new policy. The left panel in Figure 3 confirms this claim for $\alpha=4$ when a policy renouncement occurs in period $2\left(x_{2}=D\right.$ and $\left.x_{t}=C \forall t \neq 2\right)$ or period $3\left(x_{3}=D\right.$ and $\left.x_{t}=C \forall t \neq 3\right)$. One could therefore infer that in times of a deep recession, policy commitments are not relevant: the interest rate will be at zero irrespective of policy renouncements. However, such inference is misguided. The promise of a low interest rate is made because of its positive effects throughout the entire recession. If the interest rate policy is reformulated in the midst of the recession, the incentive to keep the 
interest rate low is reduced. In fact, if policy renouncements occur in the early phase of the recession, the economy exits the zero bound earlier. Commitment is important well before the central bank faces the temptation to start tightening the contemporaneous interest rate.

Figure 3: Imperfect Credibility and the Zero Lower Bound - Reneging on Promises
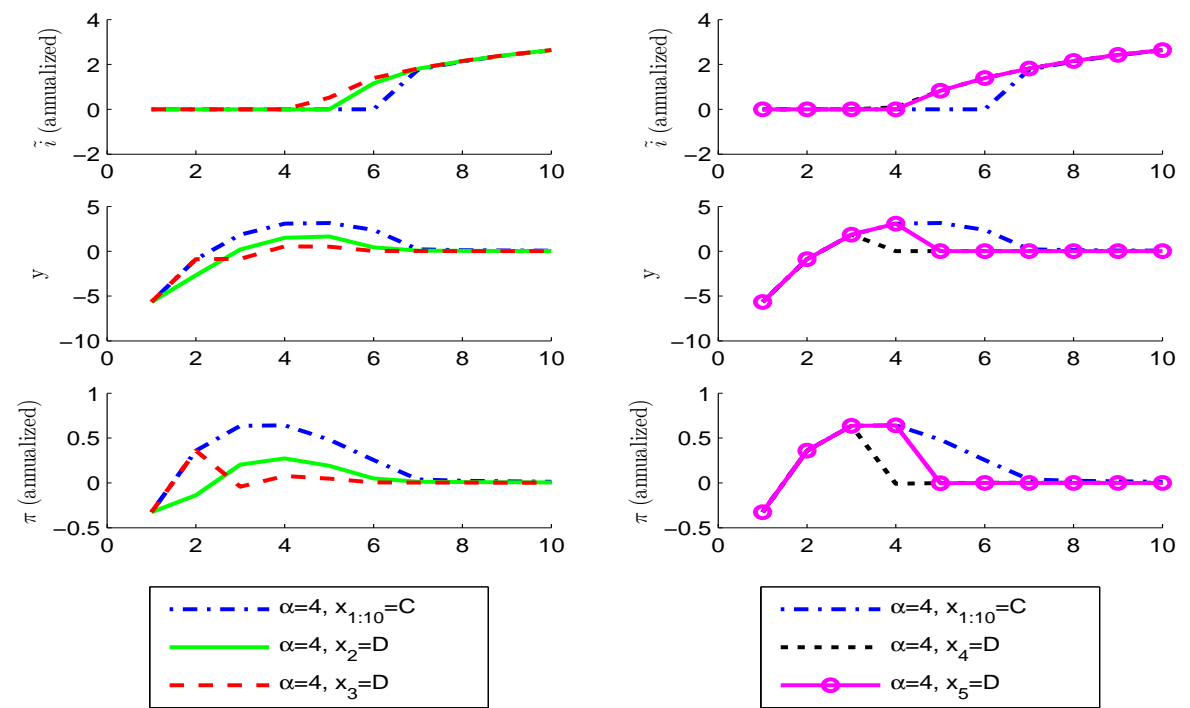

\begin{abstract}
Notes: the figure plots the transition dynamics in response to a negative and large demand shock causing the interest rate to reach its zero lower bound. The shocks are initialized at $u_{1}=0, g_{1}=-10$, and $\left(\varepsilon_{u, t}, \varepsilon_{g, t}\right)=0 \forall t \geq 2$. All cases refer to imperfect credibility with $\alpha=4$. The dot-dashed line in both panels refers to the specific history $x_{t}=C \forall t$. The remaining lines in the figure plot a specific history $x_{t}=C \forall t \neq m$, with $m \in\{2,3,4,5\}$.
\end{abstract}

While the economy is on its recovery path, the interest rate may still be zero due to earlier commitments. As depicted in the right panel of Figure 3, the central bank raises the interest rate immediately if a default occurs in this phase. For defaults in period $4\left(x_{4}=D, x_{t}=C\right.$ $\forall t \neq 4)$ or $5\left(x_{5}=D, x_{t}=C \forall t \neq 5\right)$, such action puts an end to the policy of elevated inflation and output gap previously promised and brings both variables closer to target.

Once the economy has exited from the zero bound, it is immaterial whether new commitments are made after a policy renouncement. After exiting from the zero lower bound, commitments hardly have additional value with respect to the demand shocks. Figure 4 shows that after a default in period 6 , the projected path with $x_{t}=C \forall t \geq 7$ and the path with 
$x_{t}=D \forall t \geq 7$ overlap. $^{15}$

Figure 4: Imperfect Credibility and the Zero Lower Bound - After Reneging on Promises
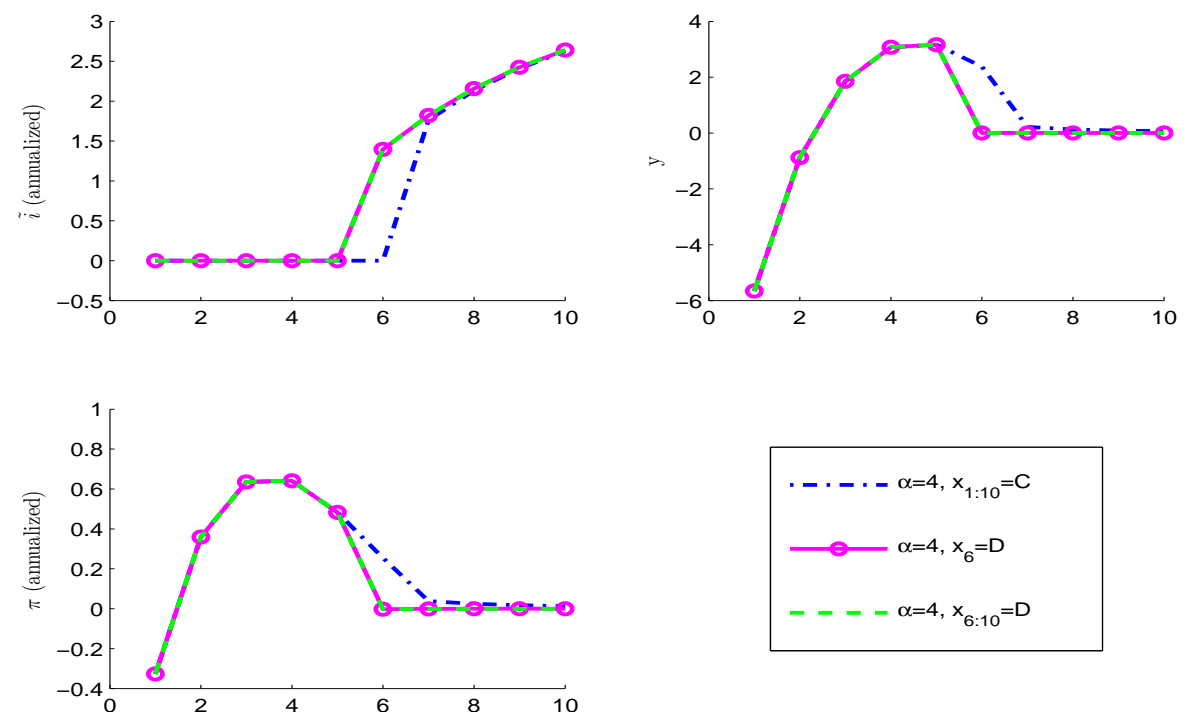

Notes: the figure plots the transition dynamics in response to a negative and large demand shock causing the interest rate to reach its zero lower bound. The shocks are initialized at $u_{1}=0, g_{1}=-10$, and $\left(\varepsilon_{u, t}, \varepsilon_{g, t}\right)=0 \forall t \geq 2$. All cases refer to imperfect credibility with $\alpha=4$. The first line plots the specific history $x_{t}=C$ $\forall t$; the second line plots the specific history $x_{t}=C \forall t \neq 6$; the third line plots the specific history $x_{t}=C \forall t<6$.

\subsubsection{Temptation and Welfare}

The exact nature of the time inconsistency problem faced by the central bank is illustrated by the welfare analysis in Figure 5. We plot the welfare gain from a random default in period T relative to staying committed, $V_{T, x_{T}=D}-V_{T, x_{T}=C} \cdot V_{T, x_{T}}$ is the present discounted value of the central bank's utility from $\mathrm{T}$ onwards with realization $x_{T} \cdot{ }^{16}$ In period 1 , the economy experiences a large contractionary demand shock, $g_{1}=-10$, that pushes the interest rate down

\footnotetext{
${ }^{15}$ In creating Figure 4, we set $x_{t}=C \forall t \leq 5$. Furthermore, the realized values of the shocks to demand and costs are zero after period 1. If the economy experiences additional shocks after exiting the zero bound, new commitments can be important.

${ }^{16}$ For a fixed default probability $\eta$, the central bank achieves higher utility in a given period when reoptimization occurs. In equation (9) the last two terms make the problem recursive but are not welfare relevant. In the computations we consider only the welfare relevant terms, which would be equivalent to computing the discounted sum of the period utility function in equation (6).
} 
to zero. Afterwards no cost-push or demand shocks realize. In all periods prior to period T, the policymaker is assumed to honor her promises.

Figure 5: Welfare Gains from Default

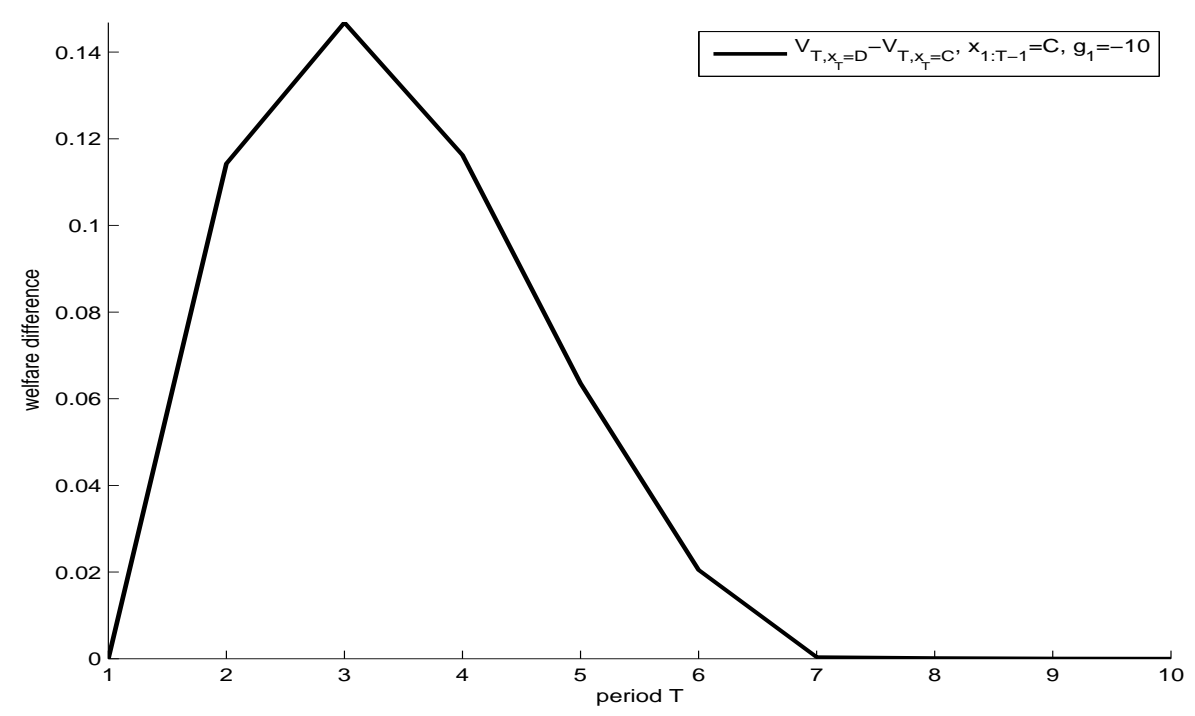

Notes: the figure plots the period $T$ expectation of the gain in discounted welfare due to a default in period $T$, for the case of imperfect credibility with $\alpha=4$ and the specific histories $x_{t}=C \forall t<T$. The shocks are initialized at $u_{1}=0, g_{1}=-10$, and $\left(\varepsilon_{u, t}, \varepsilon_{g, t}\right)=0 \forall t<T$.

The temptation to renege is the highest in period 3. Revisiting Figure 3 reveals that defaulting in period 3 avoids the costly overshooting of inflation and the output gap. The economy is stabilized more effectively if the opportunity to re-optimize occurs in this period rather than in any other.

\subsection{Distribution of Responses}

To highlight specific features of our model, the impulse response functions shown so far have been based on specific histories for $x_{t}, \varepsilon_{g, t}$, and $\varepsilon_{u, t}$. For the next two experiments, we analyze more generally the distribution of impulse responses at the zero bound.

First Experiment We first restrict attention to histories with $g_{1}=-10$ and $\varepsilon_{g, t}=0$ $\forall t \geq 2$, and $u_{1}=0$ and $\varepsilon_{u, t}=0 \forall t \geq 2$, but allow for all possible histories of $x_{t}$. Figure 6 shows the mean impulse response under imperfect credibility with $\alpha=4$ surrounded by the impulse 
response functions lying between the $5 t h$ and $95 t h$ percentiles, the shaded area. The figure also displays the impulse responses when the policymaker has full commitment or acts under full discretion, respectively. As we still condition on a specific history for the demand and cost-push shocks, there is no uncertainty about the impulse responses under full commitment and full discretion.

Figure 6: Distribution of Impulse Response Functions - Default Uncertainty Only
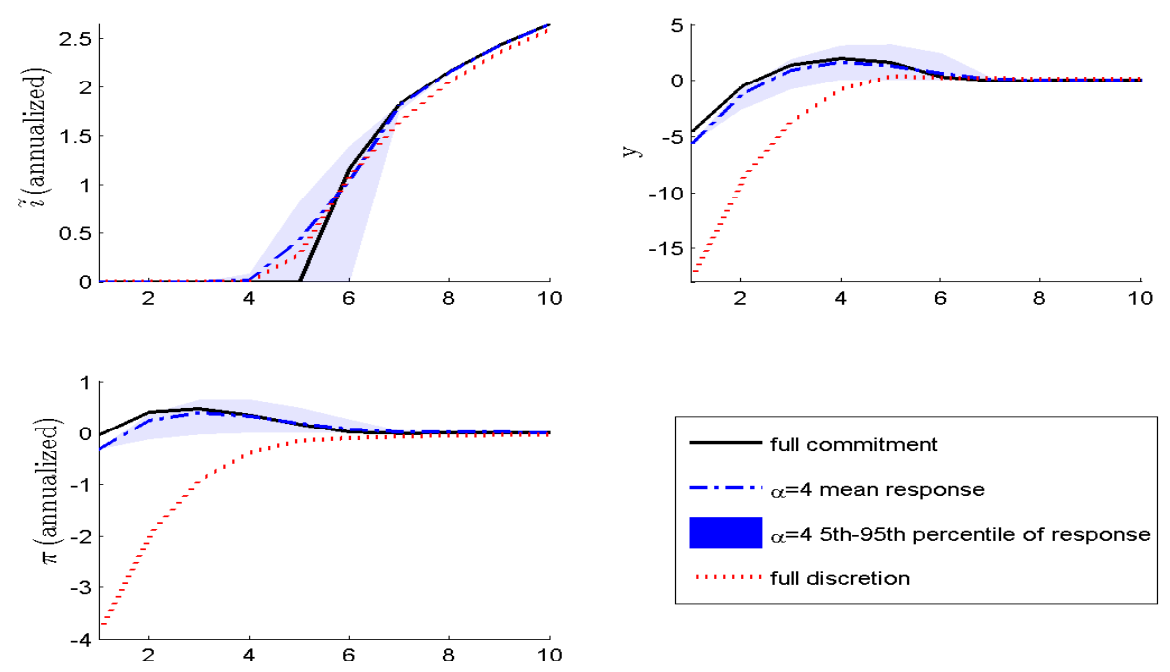

Notes: the figure plots the transition dynamics in response to a negative and large demand shock causing the interest rate to reach its zero lower bound. The shocks are initialized at $u_{1}=0, g_{1}=-10$, and $\left(\varepsilon_{u, t}, \varepsilon_{g, t}\right)=0 \forall t \geq 2$. The mean and selected percentiles are computed from simulated histories of the commitment shock (i.e. $\left.x_{t} \in\{C, D\}\right)$. For the full commitment and full discretion cases, there is no uncertainty with regard to $x_{t}$ shocks, and therefore any percentile coincides with the mean.

For the mean response under imperfect credibility, the path of the interest rate is higher at least in the near term than both under full commitment and full discretion. ${ }^{17}$ Nevertheless, the output gap and inflation rise above target before returning to it for the mean response under limited credibility as is the case under full commitment. However, this mean response is surrounded by considerable uncertainty. The shaded area spanned by the 5 th and 95th percentile responses covers the special cases depicted in Figures 2 through 4 . These scenarios

\footnotetext{
${ }^{17}$ Our results remain largely unaffected when replacing the mean by the median of the impulse responses.
} 
showed that imperfect credibility may lead to large and persistent positive or negative deviations of the output gap and inflation from their long-run target values.

As in the full discretion case, the impulse response functions for histories with many default events do not imply a post-recession boom with inflation. However, for our benchmark calibration of $\alpha=4$, the economy does not perform as poorly as the economy under full discretion, in which the policymaker re-optimizes every period. Thus, being somewhat committed but defaulting in many periods by chance, is different from being known to have no commitment at all. Consequently, even central banks with low credibility should attempt to use forward guidance to the best of their ability rather than giving up on this tool completely.

Second Experiment We consider all possible histories for $x_{t}, \varepsilon_{g, t}$, and $\varepsilon_{u, t}$ for $t>1$. For the initial period, $t=1$, however, we distinguish two cases. In the first case, the economy experiences a large negative demand shock that pushes the nominal interest rate to zero, i.e., $g_{1}=-10, u_{1}=0$, whereas for the second case we initialize the economy at $g_{1}=0, u_{1}=0$.

Figure 7 plots the interquantile range between the $95 t h$ percentile response and the $5 t h$ percentile response when policymakers act under full commitment, imperfect credibility $(\alpha=4)$, and full discretion. The dashed lines depict the interquantile ranges when the economy is initially at the zero bound $\left(g_{1}=-10\right)$ and the solid lines depict the case when the economy is initialized at $g_{1}=0$.

The economy experiences higher uncertainty about the future paths of the output gap and the inflation rate as measured by the interquantile range when the economy is initially at the zero lower bound. Monetary policy can no longer counteract shocks as effectively as it can when the interest rate is positive. The resulting increase in the economy's sensitivity to shocks translates into (temporarily) increased uncertainty about the output gap and the inflation rate. As the nominal interest rate is the predominant shock absorber when the interest rate is positive, the uncertainty about the future path of the nominal interest rate is lower when the economy is initially at the zero bound. ${ }^{18}$ For periods further in the future, the interquantile ranges for

\footnotetext{
${ }^{18}$ Among others, Eggertsson (2006) and Bodenstein et al. (2009) have pointed out the increased sensitivity of the economy to additional shocks once the policy interest rate has reached zero. However, as most authors have abstained from employing global methods in solving their models, earlier work does not show the rise in
} 
Figure 7: Forecast Uncertainty - Interquantile Range
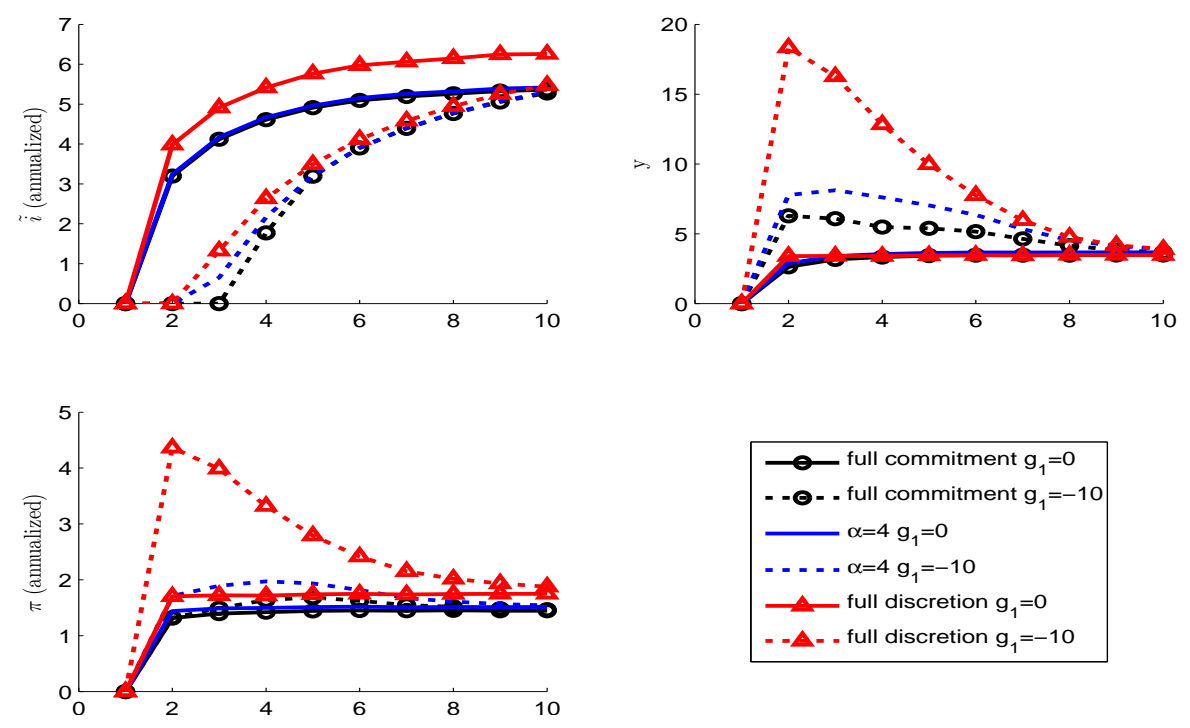

Notes: the figure plots the difference between the 95th and 5th percentiles in several scenarios. In all simulations, the shocks $\left(\varepsilon_{u, t}, \varepsilon_{g, t}, x_{t}\right)$ are drawn from their respective distributions. For the cases reported with the solid lines, the simulations are initialized at $u_{1}=0, g_{1}=0$. For the cases reported with the dashed lines, the simulations are initialized at $u_{1}=0, g_{1}=-10$, which causes the interest rate to reach its zero lower bound. For the full commitment and full discretion cases, there is no uncertainty with regard to $x_{t}$ shocks.

the two cases $\left(g_{1}=-10\right.$ and $\left.g_{1}=0\right)$ converge as it is less likely for the zero bound to remain binding for the case with $g_{1}=-10$ once the initial demand shock has sufficiently receded.

Policy commitment is especially important when the economy is at the zero bound. For an interest rate of zero, the interquantile ranges for inflation and the output gap are substantially higher in an economy with imperfect credibility compared to an economy with full commitment. Doubts about the commitment of the central bank impinge upon its ability to use interest rate announcements for forward guidance. ${ }^{19}$ Away from the zero bound, by contrast, there is little difference regarding the interquantile ranges for the two policy regimes $(\alpha=4, \alpha=\infty)$. In the 2008/2009 recession, markets have experienced increased volatility and uncertainty in the inflation and output outlook. Our findings suggest that part of this uncertainty is a consequence uncertainty explicitly.

${ }^{19}$ Under full discretion the increase in uncertainty is most pronounced. As the monetary authority re-optimizes every period, no forward guidance can be provided. 
of the zero lower bound and low credibility.

\section{Credibility and Times of Crisis}

Actions by politicians, central bank officials, and financial markets during the sharp worldwide downturn in economic activity 2008/2009 have created doubt about how much credibility central banks actually have. In this section, we present suggestive evidence for this claim and discuss to what extent this evidence is in line with the predictions from our model.

\subsection{Credibility and Increased Uncertainty}

If the central bank has low credibility, the announced interest rate path of the central bank can differ significantly from the market expectations for the interest rate at the zero lower bound. For the case of $\alpha=2$, Figure 8 shows two paths in each panel. The first path depicts the mean over all possible histories of the cost-push, demand, and default shock. The second path depicts the mean over all possible histories of the cost-push and demand shock, but assumes that the central bank honors by chance its state-contingent commitments in each period, i.e., $x_{t}=C \forall t \geq 1$.

In reality, central banks may be more optimistic than the market about their ability to keep future promises. Based on our discussion of Figure 2, it is also in the interest of central banks to announce their commitment path in order to influence expectations. Consequently, we interpret the first path (solid line) in Figure 8 as reflecting market expectations and the second path (dash-dotted line) as the announced forecast of the central bank. The announced (mean) interest rate forecast of the central bank lies strictly below the mean interest rate forecast of the private sector, as the latter takes into account all future re-optimizations. Consistent with a tighter expected monetary policy path, the market also expects a smaller rise in the output gap and a smaller rise in inflation. ${ }^{20}$ Away from the zero lower bound, the mean paths of the central bank and the private sector basically coincide. ${ }^{21}$ This prediction of our model fits well

\footnotetext{
${ }^{20}$ The same qualitative result emerges for $\alpha=4$, but the misalignment between the two paths is less pronounced.

${ }^{21}$ When interest rates can freely adjust, the role of the default shock still affects interquantile ranges.
} 
Figure 8: Forecasts and Policy Renouncements
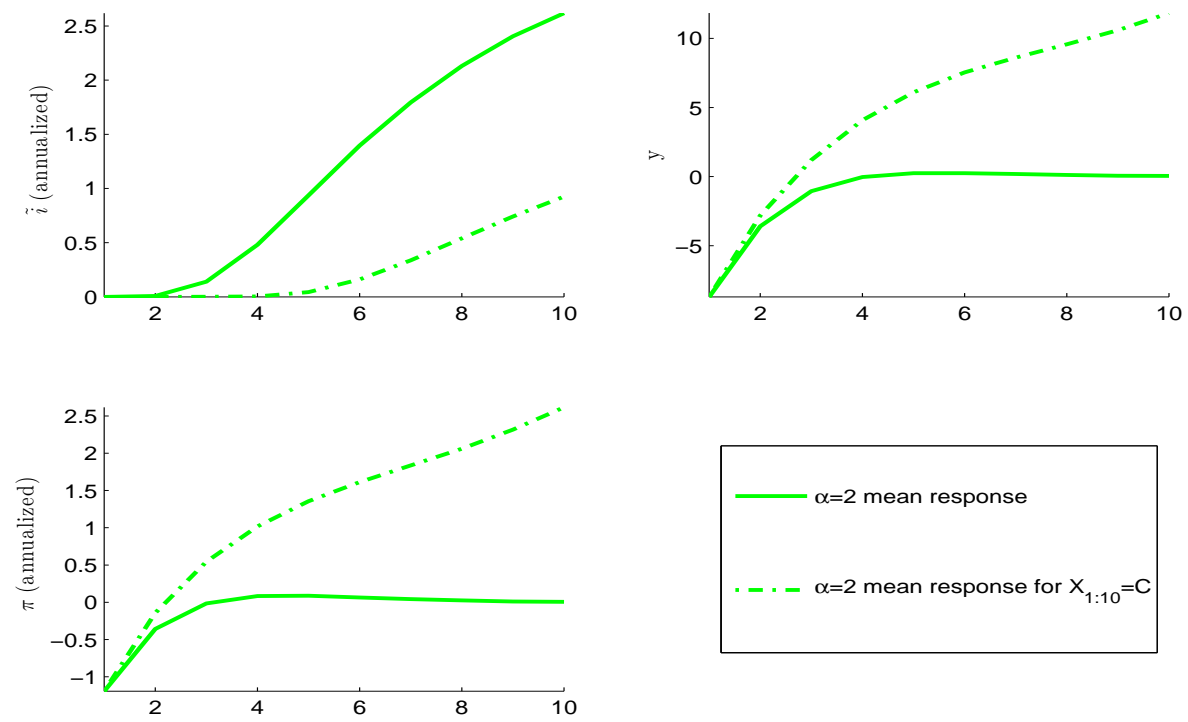

Notes: the figure plots the mean transition dynamics in response to a negative and large demand shock causing the interest rate to reach its zero lower bound. The simulations are initialized at $u_{1}=0, g_{1}=-10$. For the case of the solid line, the shocks $\left(\varepsilon_{u, t}, \varepsilon_{g, t}, x_{t}\right)$ are drawn from their respective distributions. For the case of the dot-dashed line, the shocks $\left(\varepsilon_{u, t}, \varepsilon_{g, t}\right)$ are similarly drawn from their respective distributions, but with $x_{t}=C \forall t \geq 1$.

with recent experience of the Swedish Riksbank.

Since February 2007, the Riksbank has published its intended (mean) path for the repo-rate, the short-term interest rate used by the Riksbank to achieve its policy goals. ${ }^{22}$ To assess the predictability of its policies, the Riksbank also publishes the market expectation for the interest rate path derived from forward rates. ${ }^{23}$ Figure 9 plots the mean of the repo-rate path and the mean of market expectations before and after the February 11 and April 212009 meetings.

On February 11, the interest rate was reduced by 100 basis points to $1 \%$. As was the case on earlier dates, the new repo-rate path and market expectations were aligned. At the April

\footnotetext{
${ }^{22}$ Similar to other central banks that publish an interest rate forecast, the Riksbank emphasizes the conditional nature of its forecast, i.e., the Riksbank may deviate from the announced path in the future as unexpected shocks hit the economy. Svensson (2010) argues that the private sector seems to understand the contingent nature of the announcement. In addition to its mean forecast, the Riksbank also shows uncertainty intervals around its central forecast.

${ }^{23}$ The market expectations of the repo-rate are calculated as the forward rate from the prices of interest derivatives and forward rate agreements with different maturities corrected for premia for maturity, liquidity and credit risk. Sveriges Riksbank (2009) and Svensson (2009, 2010) provide more details on the data and draw connections to credibility and forecast targeting at different times.
} 
21 meeting, the repo-rate was reduced further and approached the effective lower bound. This time, the repo-rate path and market expectations decoupled, as market expectations suggested much faster tightening. These patterns are also present at later dates in 2009 (not displayed); market expectations are not aligned with the repo-rate path only in periods of very low interest rates. ${ }^{24}$ Thus, our model can broadly explain the observed misalignment of interest rate paths in Sweden and therefore suggests that the Riksbank has experienced a credibility problem. In fact, the Riksbank concedes this possibility in its annual monetary policy report, Sveriges Riksbank (2009).

Figure 9: Low Credibility and Market Expectations

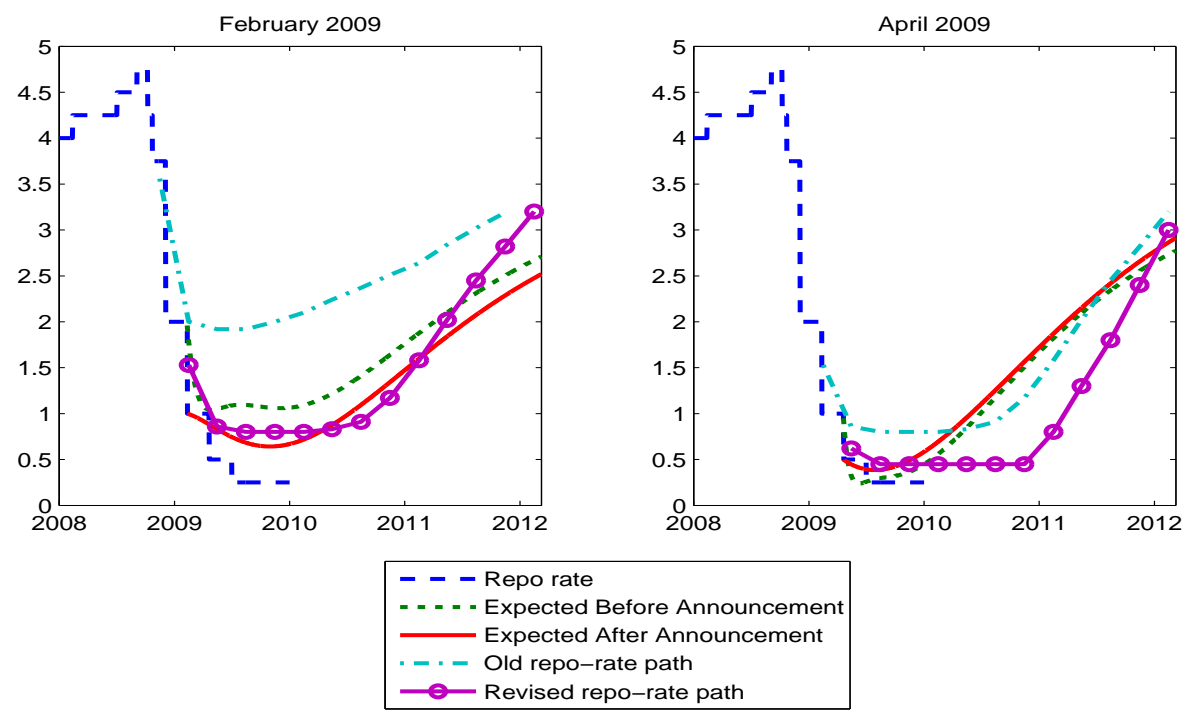

Notes: the figure plots the Riksbank's revised forecast of the repo-rate path as announced in February and April 2009 in the left and right panels, respectively, along with the old forecast, the historical path, and the market expectation of the path both preceding and following each announcement.

An alternative explanation for the misalignment rests on forecast divergence with respect to GDP growth and inflation between the Riksbank and the private sector. If credibility was not an issue and if the markets expected inflation and output to recover faster, then they could

\footnotetext{
${ }^{24}$ For reasons not considered in the model, central banks are often reluctant to set interest rates exactly at zero and operate with a positive lower bound. Although the repo-rate was lowered to 25 basis points later in 2009, the Riksbank argued in April 2009 that 50 basis point would be the lowest operational level for the repo-rate.
} 
Figure 10: Private sector and central bank's forecasts in Sweden
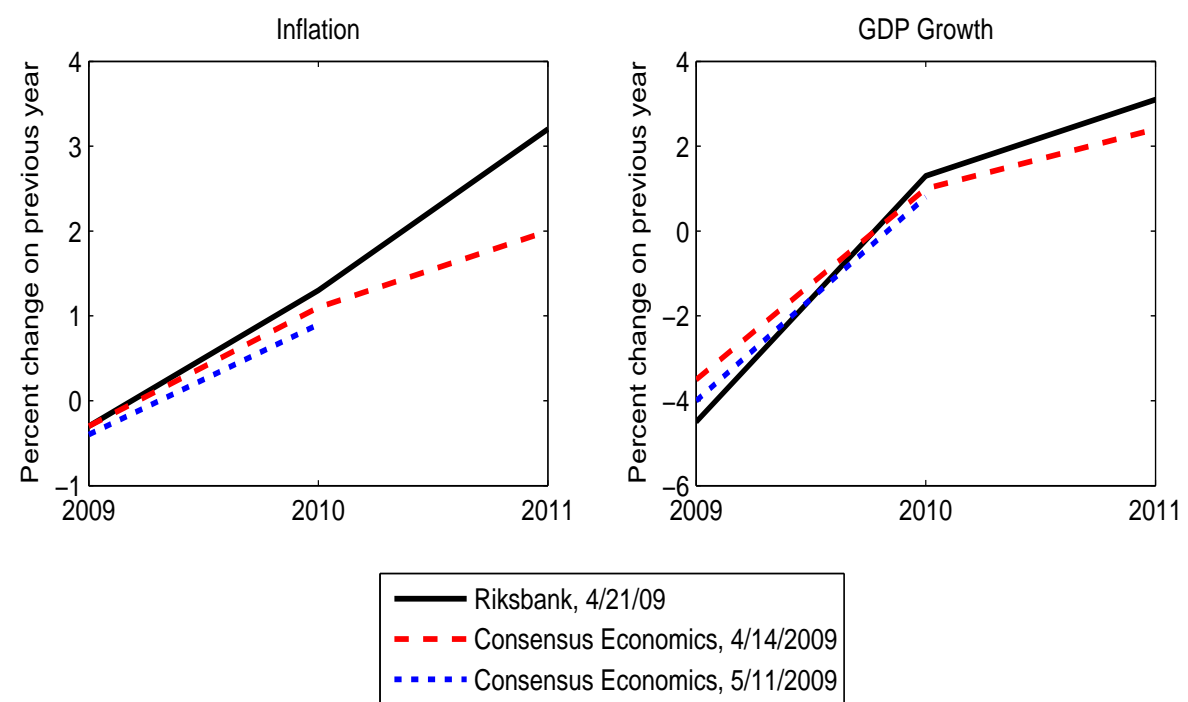

\begin{abstract}
Notes: the figure plots the Riksbank's forecasts for Inflation and GDP Growth announced on April 21, 2009 (Sources: Statistics Sweden and the Riksbank). We also show means of long-term forecasts surveyed on April 14, 2009 and nearer-term forecasts surveyed on May 11, 2009 (Sources: Consensus Economics' April 2009 and May 2009 issues of Consensus Forecasts).
\end{abstract}

expect as well a faster interest rate increase. However, as shown in Figure 10, in April 2009 the inflation and GDP growth outlook reported by Consensus Economics (both on April 14 and May 11) were below the Riksbank's forecast (April 21) for these variables. As the market expectations for the repo-rate before and after April 21 are seemingly unchanged in Figure 9, and the private sector outlook in May seemed even grimmer than in April, we discard the idea that market optimism about GDP growth and inflation led to diverging views about the future path of the interest rate. In fact, Figure 10 seems to indicate that market expectations were more pessimistic, which is in accordance with the explanation of lack of credibility shown in Figure 8. 


\subsection{Central Bank Statements}

Current Federal Reserve policy simultaneously promises to keep the interest rate low and to prevent inflation from rising. ${ }^{25}$ As pointed out by Walsh (2009), such policies are inconsistent with the optimal policy under full commitment. However, these two policies are not mutually exclusive under imperfect credibility. It is because of its imperfect credibility that the central bank makes an even more extreme promise to leave the interest rate low (see Figure 2). At the same time, the policymaker knows that with positive probability the policy path will be re-optimized to avoid the rise in inflation (see Figure 3).

The previous line of reasoning appeals to different histories of the commitment shock to rationalize different policies. However, the analysis with the mean response also suggests that the level of credibility $\alpha$ is low. Kohn (2009b) states: "To be sure, we have not followed the theoretical prescription of promising to keep rates low enough for long enough to create a period of above-normal inflation." The intention of U.S. policymakers not to allow a period of above normal inflation can be interpreted through the lens of our model. Figure 11 plots the mean impulse responses to a large contractionary demand shock that pushes the interest rate to the zero bound for different degrees of policy credibility. The mean response does not entail a significant rise of the output gap and inflation above their long-run target levels for $\alpha<1.25$. While there are may be other interpretations, our analysis suggests that statements as in Kohn (2009b) reflect a low degree of credibility under the assumption that the New Keynesian model applies.

In particular, policymakers seem to emphasize fear of losing control over inflation expectations to justify their position. ${ }^{26}$ However, such fears can also be rationalized in our model as

\footnotetext{
${ }^{25}$ See statements in Kohn (2009a) and Bernanke (2009).

${ }^{26}$ Kohn (2009b) continues: "The arguments in favor of such a policy hinge on a clear understanding on the part of the public that the central bank will tolerate increased inflation only temporarily - say, for a few years once the economy has recovered - before returning to the original inflation target in the long term. In standard theoretical model environments, long-run inflation expectations are perfectly anchored. In reality, however, the anchoring of inflation expectations has been a hard-won achievement of monetary policy over the past few decades, and we should not take this stability for granted. Models are by their nature only a stylized representation of reality, and a policy of achieving "temporarily" higher inflation over the medium term would run the risk of altering inflation expectations beyond the horizon that is desirable. Were that to happen, the costs of bringing expectations back to their current anchored state might be quite high." See also former Fed
} 
Figure 11: Average Recovery Path for Different Commitment Levels
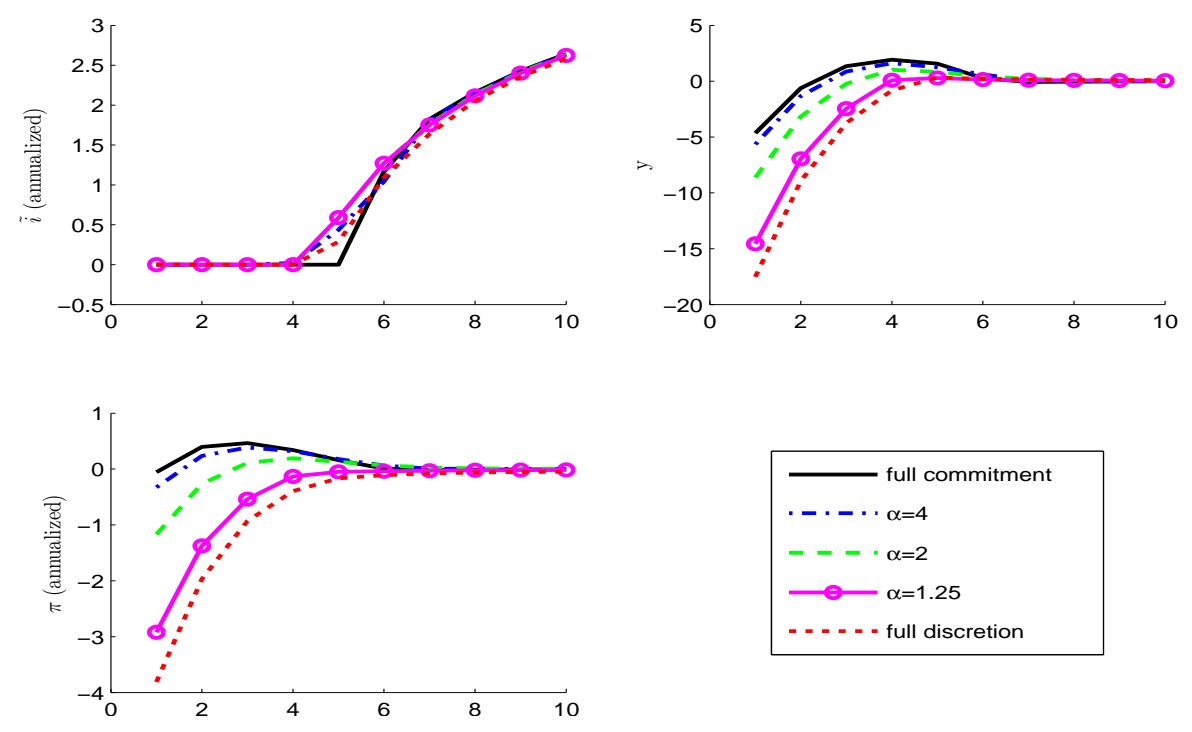

Notes: the figure plots the mean transition dynamics in response to a negative and large demand shock causing the interest rate to reach its zero lower bound. The shocks are initialized at $u_{1}=0, g_{1}=-10$, and $\left(\varepsilon_{u, t}, \varepsilon_{g, t}\right)=0 \forall t \geq 2$. All histories regarding the commitment shock are considered (i.e. $x_{t} \in\{C, D\}$ ) for the computation of the means. For the full commitment and full discretion cases, there is no uncertainty with regard to $x_{t}$ shocks.

reflecting low credibility. Although long-run inflation expectations are well-anchored for any degree of credibility, inflation can be hard to control in the medium-run if credibility is low. A related possibility is that central banks favor models in which a large fraction of agents are backward looking or employ learning mechanisms. Nevertheless, insofar as some agents are forward looking, such features dampen the post-recession inflation but do not eliminate it. However, central bank statements dismiss the idea of above normal inflation and output altogether rather than claiming that these effects are of small magnitude. Furthermore, the private sector choosing to dismiss announcements and engaging in backward looking behavior may also be a consequence of low central bank credibility. ${ }^{27}$

Governor Mishkin in Mishkin (2009).

${ }^{27}$ Evans and Ramey (1992), Brock and Hommes (1997) and the literature that followed model private agents as choosing among different predictors based on their performance and availability. If the central bank disseminates and produces credible forecasts, then a larger fraction of private agents is likely to form rational expectations (see the discussions in Tobin (1972) and Sargent et al. (1973)). 


\subsection{Pressures on Policymakers}

Since the beginning of the 2008/2009 recession, the Federal Reserve System has encountered unprecedented attacks on its independence. ${ }^{28}$ Financial market commentators have repeatedly urged the Federal Reserve to raise interest rates for fear of increased future inflation. ${ }^{29}$ And Federal Reserve Chairman Ben Bernanke himself said in a Time Magazine article honoring him as "Person of the Year 2009": "It is true that the Federal Reserve faces a lot of political pressure and is unpopular in many circles."

Why has the political pressure on the Federal Reserve intensified so much during this crisis, although credibility and central bank independence are perceived to be important building blocks in mitigating the effects of the downturn? One possible answer is provided in Figure 12. We plot the difference between the value of staying committed in period $\mathrm{T}, V_{T, x_{T}=C}$, and the value of defaulting in period $\mathrm{T}, V_{T, x_{T}=D}$, both for an economy that has been hit by a large negative demand shock $\left(g_{1}=-10\right)$ and an economy that is initialized at $g_{1}=0 .{ }^{30}$ Although commitment is extremely important in times of crisis, this is also the time when the time inconsistency problem becomes exacerbated. In Figure 12, the welfare gain from reneging on an earlier promise is significantly higher at every point in time when the economy is in a severe recession compared to the case of $g_{1}=0$.

Admittedly, some of the public criticism of the Federal Reserve has focused on issues other than the future path of the Federal Funds rate which we have used to illustrate our concerns. Nevertheless, many legislative changes and suggestions coming out of the U.S. Congress could directly or indirectly impact future conduct of monetary policy. In reaction to these developments, Goodfriend (2010) has laid out a detailed plan to ensure that the Federal Reserve remains a strongly independent institution.

\footnotetext{
${ }^{28}$ Suggestions for how to curb the power of the Fed have ranged from stripping it of its regulatory powers, changing the selection procedures of the president of the New York Fed, to having its monetary policy decisions audited by the Government Accountability Office. Since we started writing this paper some of these suggestions have been put into law.

${ }^{29}$ For a discussion of these fears see http://www.nytimes.com/2009/05/29/opinion/29krugman.html.

${ }^{30}$ In Figure 12, the innovations and default shocks $\left(\varepsilon_{u, t}, \varepsilon_{g, t}, x_{t}\right)$ are set to be the same across scenarios.
} 
Figure 12: Pressure to Default

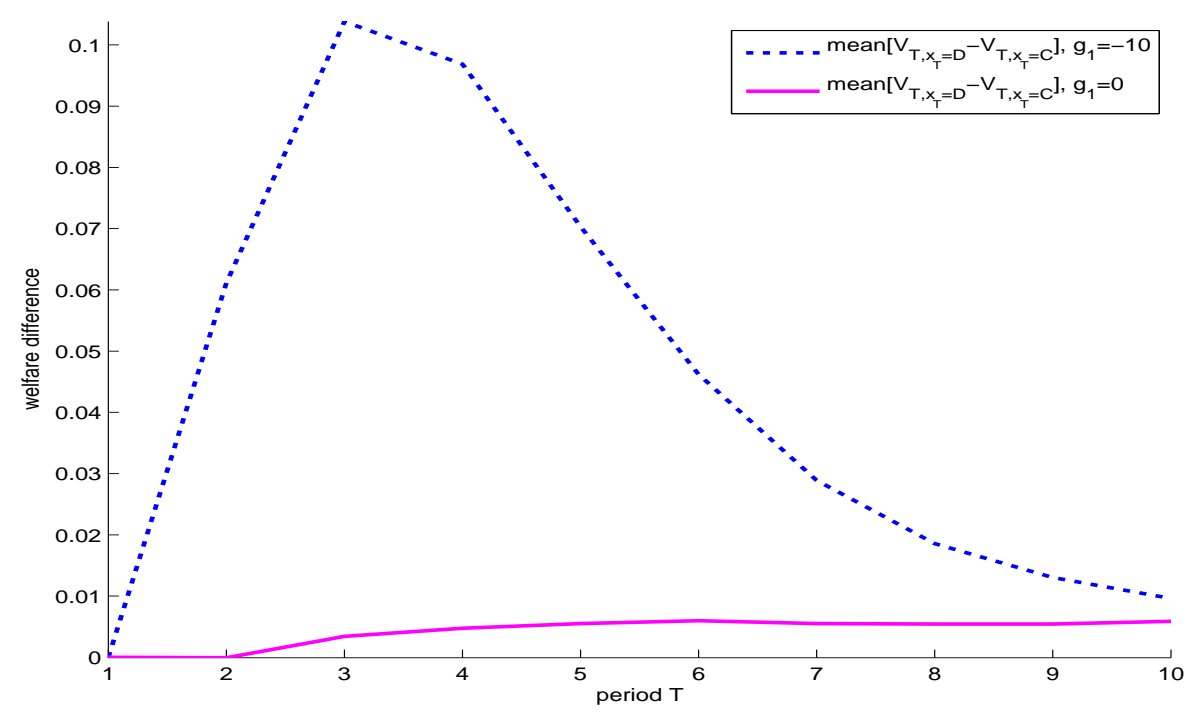

Notes: the figure plots the mean period $T$ expectation of the gain in discounted welfare due to a default in period $T$, in simulations of imperfect credibility with $\alpha=4$. In all simulations, the shocks $\left(\varepsilon_{u, t}, \varepsilon_{g, t}, x_{t}\right)$ are drawn from their respective distributions. For the cases represented by the dotted line and the solid line, simulations are initialized at $u_{1}=0, g_{1}=-10$ and $u_{1}=0, g_{1}=0$, respectively.

\section{$5 \quad$ Sensitivity Analysis}

In this section, we conduct two robustness exercises with respect to partial price indexation and the intertemporal elasticity of substitution.

\subsection{Indexation}

Galí and Gertler (1999) and several other empirical studies have found that inflation dynamics are also affected by backward looking behavior. Hence, this section considers a hybrid Phillips curve with partial indexation. A firm $j$ that is not allowed to optimally reset its price in the current period adjusts the price mechanically by:

$$
\log p_{t}(j)=\log p_{t-1}(j)+\zeta \pi_{t-1}
$$

Appendix A.1 describes the Phillips curve, the objective function, and the solution method with indexation. Introducing indexation significantly complicates the solution method. First, 
lagged inflation increases the number of state variables to 5. Second, inflation can now be used strategically to influence future decisions. The central bank anticipates future decisions and understands that, although it cannot commit to future actions, it can affect future decisions through the inflation process. In the solution procedure, this strategic interaction means that both the level and the derivative of the policy function need to be accounted for.

Figure 13 repeats the exercise shown in Figure 6 for an indexation parameter $\zeta$ equal to 0.14. ${ }^{31}$ The qualitative features pointed out earlier remain unchanged. Quantitatively, price indexation reinforces the problems posed by the zero bound constraint. Indexation is particularly painful for a discretionary central bank because the central bank already cannot control expectations and now price indexation adds momentum.

Figure 13: Distribution of Impulse Response Functions - Default Uncertainty Only - Indexation
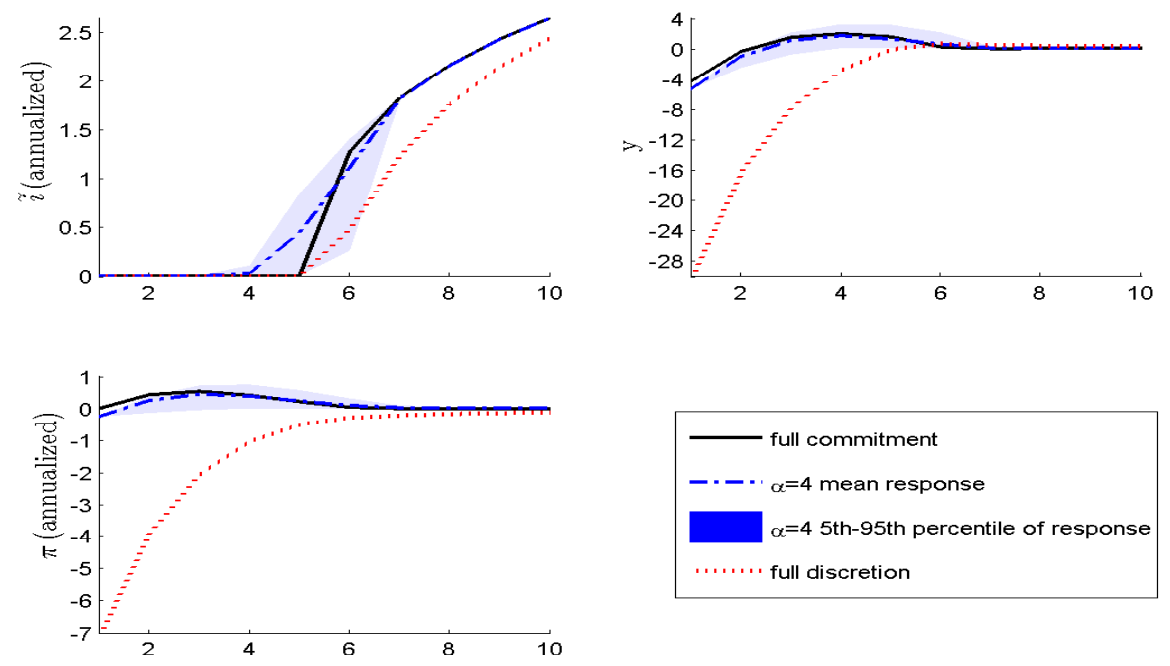

Notes: see notes to figure 6 . The indexation parameter is $\zeta=0.14$

Both with and without price indexation, a central bank with high credibility promises and implements an interest rate path that supports a post-recession boom with elevated inflation and a positive output gap. A monetary authority that acts under full discretion does not allow

\footnotetext{
${ }^{31}$ For values of $\zeta>0.14$ the solution algorithm does not converge for all cases. For high values of $\zeta$ and low credibility the recession and the deflation can be quite severe, creating convergence problems in the algorithm. Adam and Billi (2007) also report similar issues.
} 
inflation and the output gap to exceed their target levels. In contrast to Figure 6, the observed interest rate under full discretion never lies above the interest rate under full commitment when prices are partially indexed. Thus, a low observed interest rate does not reveal high credibility. The committed policymaker can avoid a deep recession and still implement a higher path of the interest rate because her commitments are conditional on future economic outcomes. If an additional shock occurred, the central bank would adjust the promised interest rate path in accordance with its credible and fully state contingent plan. ${ }^{32}$ Unable to make highly credible state contingent promises, a monetary authority with low credibility falls into a deep recession to which partial indexation adds momentum. As a result, the observed interest rate path remains below the interest rate path shown under full commitment.

The incentives and effects of renouncements under imperfect credibility cannot be inferred by simply comparing the full commitment and full discretion case. Although the interest rate path under full discretion is kept below the path under full commitment, a renouncement under imperfect credibility still implies higher interest rates than promised earlier.

\section{$5.2 \quad$ Intertemporal elasticity of substitution}

Our baseline value for the intertemporal elasticity of substitution $(\sigma)$ has been 6.25 . In line with the literature, a high value of $\sigma$ is supposed to capture interest rate sensitive demand for investment that is not modeled explicitly. However, a literal interpretation of our model requires a lower value of $\sigma$. Figure 14 plots the distribution of impulse response functions with default uncertainty only for $\sigma=5.00$ and $\sigma=6.25 .^{33}$ As stated in equation (2), the demand shock $g$ affects aggregate demand equally irrespective of the value of $\sigma{ }^{34}$

With a lower value of $\sigma$, the nominal interest rate must be adjusted more aggressively in

\footnotetext{
${ }^{32}$ This reasoning is supported by the fact that under perfect foresight and partial indexation, a fully committed central bank implements an interest rate path that lies below the path implemented by a policymaker acting with full discretion.

${ }^{33}$ For values of $\sigma<5$ the solution algorithm does not converge for all cases. For low values of $\sigma$, the nominal interest rate may stay at zero for a very extended period in a deep recession, preventing our algorithm from converging. To circumvent this problem, one could reduce $\sigma_{g}$ and consider alternative calibrations. We opted to leave all the other parameters unchanged to facilitate comparisons.

${ }^{34}$ If $g$ was multiplied by $\sigma$, the effective shock to the economy would be reduced for lower values of $\sigma$; doing so would also imply re-calibrating $\sigma_{g}$ and the initial shock $g_{1}$.
} 
Figure 14: Impulse Response Functions - Default Uncertainty Only - sensitivity to $\sigma$
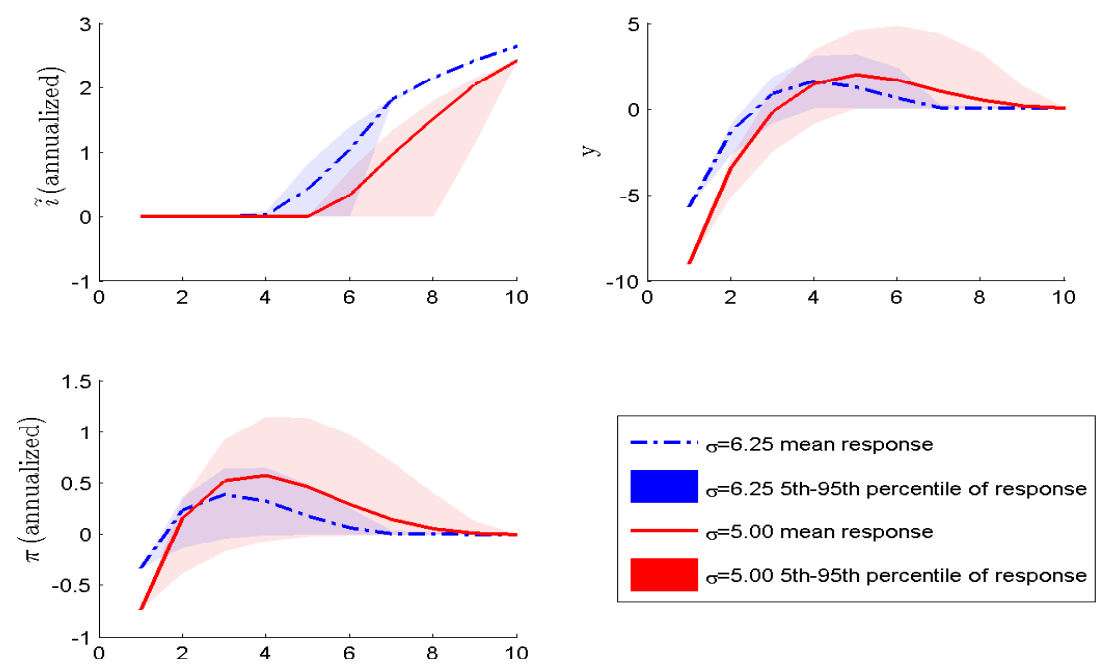

Notes: see notes to figure 6 . The intertemporal elasticity of substitution $(\sigma)$ is set to 6.25 and 5.00 .

order to affect the path of the economy and the zero lower bound constraint becomes more problematic. Therefore, for lower values of $\sigma$ the uncertainty stemming from imperfect credibility increases considerably. In period 4, the interquantile range for inflation roughly doubles. Furthermore, the central bank does not manage to stabilize the economy as effectively. The recession is more pronounced and both inflation and output rise higher above target during the post-recession boom.

\section{Conclusion}

When the interest rate reaches zero, central bank credibility and the public's perception thereof are crucial for the conduct of monetary policy. Whereas credibility matters always for monetary policy, its importance is even higher at the zero lower bound as the lack of credibility cannot be compensated for by additional movements in the contemporaneous interest rate. In reality, central banks have some credibility, but they typically do not operate under full commitment. Central banks announce and describe future policies to influence current economic 
decisions, but markets realize that not all state contingent promises will necessarily be honored. To address these issues, we analyzed the optimal monetary policy at the zero bound in a setting that allows for imperfect credibility.

Our work could be extended in several dimensions. Considering more complex models and imperfect credibility settings is desirable. For instance, central banks have also used unconventional measures to affect the economy and interest rate spreads at the zero lower bound. While incorporating such features is certainly interesting, we believe it is necessary to first understand the effects of imperfect credibility on conventional monetary policy. Furthermore, as unconventional monetary policy and fiscal policy face limits with regard to their credibility and fiscal sustainability as discussed in Goodfriend (2010), forward guidance through an announced path of the interest rate remains a tool that central banks may want to employ at the zero lower bound.

\section{References}

Adam, K., Billi, R., 2006. Optimal monetary policy under commitment with a zero bound on nominal interest rates. Journal of Money, Credit and Banking 38 (7), 1877-1905.

Adam, K., Billi, R., 2007. Discretionary monetary policy and the zero lower bound on nominal interest rates. Journal of Monetary Economics 54 (3), 728-752.

Ball, L., 1995. Disinflation with imperfect credibility. Journal of Monetary Economics 35 (1), $5-23$.

Barro, R. J., Gordon, D. B., 1983. A positive theory of monetary policy in a natural rate model. Journal of Political Economy 91 (4), 589-610.

Benhabib, J., Schmitt-Grohe, S., Uribe, M., 2001. The perils of taylor rules. Journal of Economic Theory 96 (1-2), 40-69.

Benhabib, J., Schmitt-Grohe, S., Uribe, M., 2002. Avoiding liquidity traps. Journal of Political Economy 110 (3), 535-563. 
Berger, H., Woitek, U., 2005. Does conservatism matter? a time-series approach to central bank behaviour. Economic Journal 115 (505), 745-766.

Bernanke, B., 2009. Semiannual monetary policy report to the congress. Testimony Chairman Ben S. Bernanke Semiannual Monetary Policy Report to the Congress Before the Committee on Financial Services, U.S. House of Representatives, Washington, D.C. http://www.federalreserve.gov/newsevents/testimony/bernanke20090721a.htm.

Billi, R., 2009. Optimal inflation for the U.S. economy. Federal Reserve Bank of Kansas City Working Papers RWP 07-03.

Blinder, A., 2000. Central bank credibility: Why do we care? How do we build it? American Economic Review 90 (5), 1421-1431.

Bodenstein, M., Erceg, C., Guerrieri, L., 2009. The effects of foreign shocks when interest rates are at zero. International Finance Discussion Papers 983.

Brock, W., Hommes, C., 1997. A rational route to randomness. Econometrica 65, 1059-1160.

Calvo, G., 1983. Staggered prices in a utility maximizing framework. Journal of Monetary Economics 12 (3), 383-398.

Chappell, H., Havrilesky, T., McGregor, R., 1993. Partisan monetary policies: Presidential influence through the power of appointment. The Quarterly Journal of Economics 108 (1), $185-218$.

Chari, V. V., Kehoe, P. J., 1990. Sustainable plans. Journal of Political Economy 98 (4), $783-$ 802.

Christiano, L., Eichenbaum, M., Rebelo, S., 2009. When is the government spending multiplier large?

Clarida, R., Galí, J., Gertler, M., 1999. The science of monetary policy: A new Keynesian perspective. Journal of Economic Literature 37 (4), 1661-1707. 
Debortoli, D., Nunes, R., 2006. Political disagreement, lack of commitment and the level of debt. Universitat Pompeu Fabra. Manuscript.

Debortoli, D., Nunes, R., 2010. Fiscal policy under loose commitment. Journal of Economic Theory (Forthcoming).

Del Negro, M., Eggertsson, G., Ferrero, A., Kiyotaki, N., 2009. The great escape? a quantitative evaluation of the fed's non-standard policies, mimeo, Federal Reserve Bank of New York.

Eggertsson, G. B., 2006. The deflation bias and committing to being irresponsible. Journal of Money, Credit and Banking 38 (2), 283-321.

Eggertsson, G. B., 2010. What fiscal policy is effective at zero interest rates? In: NBER Macroconomics Annual 2010, Volume 25. NBER Chapters. National Bureau of Economic Research, Inc.

Eggertsson, G. B., Woodford, M., 2003. The zero bound on interest rates and optimal monetary policy. Brookings Papers on Economic Activity 34 (1), 139-233.

Erceg, C., Lindé, J., 2010. Is there a fiscal free lunch in a liquidity trap?, mimeo, Federal Reserve Board.

Evans, G., Ramey, G., 1992. Expectation calculation and macroeconomic dynamics. American Economic Review 82, 207-224.

Galí, J., Gertler, M., 1999. Inflation dynamics: A structural econometric analysis. Journal of Monetary Economics 44 (2), 195-222.

Gertler, M., 2003. Discussion of eggerston and woodford: "the zero bound on interest rates and optimal monetary policy". Brookings Papers on Economic Activity 34 (1), 219-227.

Gertler, M., Karadi, P., 2009. A model of unconventional monetary policy, mimeo, New York University. 
Goodfriend, M., 2000. Overcoming the zero bound on interest rate policy. Journal of Money, Credit, and Banking 32, 1007-1035.

Goodfriend, M., 2010. Central banking in the credit turmoil: An assessment of federal reserve practice. Journal of Monetary Economics forthcoming.

Jung, T., Teranishi, Y., Watanabe, T., 2005. Zero bound on nominal interest rates and optimal monetary policy. Journal of Money, Credit, and Banking 37 (5), 813-836.

Kehoe, T. J., Levine, D. K., 1993. Debt-constrained asset markets. Review of Economic Studies $60(4), 865-88$.

Kohn, D., 2009a. Central bank exit policies. At the Cato Institute's Shadow Open Market Committee Metting, Washington, D.C. http://www.federalreserve.gov/newsevents/speech/kohn20091009a.htm.

Kohn, D., 2009b. Monetary policy research and the financial crisis: Strengths and shortcomings. At the Federal Reserve Conference on Key Developments in Monetary Policy, Washington, D.C. http://www.federalreserve.gov/newsevents/speech/kohn20091009a.htm.

Kydland, F. E., Prescott, E. C., 1977. Rules rather than discretion: The inconsistency of optimal plans. Journal of Political Economy 85 (3), 473-91.

Levin, A., López-Salido, D., Nelson, E., Yun, T., 2009. Limitations on the effectiveness of forward guidance at the zero lower bound. Federal Reserve Board. Manuscript.

Marcet, A., Marimon, R., 2009. Recursive contracts. Universitat Pompeu Fabra. Working Paper.

Mishkin, F., 2009. Is monetary policy effective during financial crises? American Economic Review, Papers and Proceedings 99, 573-577.

Nakov, A., 2008. Optimal and simple monetary policy rules with zero floor on the nominal interest rate. International Journal of Central Banking 4 (2), 73-127. 
Reifschneider, D., Williams, J., 2000. Three lessons for monetary policy in a low inflation era. Journal of Money, Credit, and Banking 32, 936-966.

Roberds, W., 1987. Models of policy under stochastic replanning. International Economic Review $28(3), 731-755$.

Sargent, T. J., Fand, D., Goldfeld, S., 1973. Rational expectations, the real rate of interest, and the natural rate of unemployment. Brookings Papers on Economic Activity 1973 (2), 429-480.

Schaumburg, E., Tambalotti, A., 2007. An investigation of the gains from commitment in monetary policy. Journal of Monetary Economics 54 (2), 302-324.

Schmitt-Grohé, S., Uribe, M., 2007. Optimal simple and implementable monetary and fiscal rules. Journal of Monetary Economics 54 (6), 1702-1725.

Sleet, C., 2001. On credible monetary policy and private government information. Journal of Economic Theory 99 (1-2), 338-376.

Svensson, L., 2009. Transparency under flexible inflation targeting: Experiences and challenges. Sveriges Riksbank Economic Review 1, 5-44.

Svensson, L., 2010. Policy expectations and policy evaluations: The role of transparency and communication. Sveriges Riksbank Economic Review forthcoming.

Sveriges Riksbank, 2009. Material for assessing monetary policy. www.riksbank.com, 1-58.

Tobin, J., 1972. The wage-price mechanism: Overview of the conference. In: Eckstein, O. (Ed.), The Econometrics of Price Determination Conference. Washington D.C. Federal Reserve System, pp. 5-15.

Walsh, C., 2009. Using monetary policy to stabilize economic activity. UC Santa Cruz, manuscript. 
Williams, J., 2010. Heeding daedalus: Optimal inflation and the zero lower bound. Brookings Papers on Economic Activity forthcoming.

Woodford, M., 2003. Interest and Prices: Foundations of a Theory of Monetary Policy. Princeton University Press.

Yun, T., 1996. Nominal price rigidity, money supply endogeneity and business cycles. Journal of Monetary Economics 37 (2), 345-370. 


\section{A Appendix: Model Solution}

This appendix provides the mathematical details behind our solution approach and discusses our computational implementation.

\section{A.1 The model with Indexation}

The Phillips curve with indexation is given by

$$
\pi_{t}=\frac{1}{1+\beta \zeta}\left(\kappa y_{t}+\beta E_{t} \pi_{t+1}+\zeta \pi_{t-1}+u_{t}\right)
$$

while the aggregate demand curve remains unchanged. As in Woodford (2003), the per period utility function is assumed to be

$$
U_{t}=-\left(\pi_{t}-\zeta \pi_{t-1}\right)^{2}-\lambda y_{t}^{2}
$$

Following Marcet and Marimon (2009), the problem of the monetary authority written in its Lagrangian form is given by

$$
\begin{aligned}
& V\left(\pi_{t-1}, u_{t}, g_{t}\right) \\
& =\min _{\left\{\gamma_{t}^{1}, \gamma_{t}^{2}\right\}} \max _{\left\{y_{t}, \pi_{t}, i_{t}\right\}} E_{t} \sum_{t=0}^{\infty}(\beta \eta)^{t}\left\{-\left(\pi_{t}-\zeta \pi_{t-1}\right)^{2}-\lambda y_{t}^{2}+\beta(1-\eta) E_{t} V\left(\pi_{t}, u_{t+1}, g_{t+1}\right)\right. \\
& +\gamma_{t}^{1}\left(\pi_{t}-\frac{1}{1+\beta \zeta}\left(\kappa y_{t}+\beta \eta E_{t} \pi_{t+1}+\beta(1-\eta) E_{t} \Psi^{1}\left(\pi_{t}\right)+\zeta \pi_{t-1}+u_{t}\right)\right) \\
& \left.+\gamma_{t}^{2}\left(-y_{t}+\eta E_{t} y_{t+1}+(1-\eta) E_{t} \Psi^{2}\left(\pi_{t}\right)-\sigma\left(i_{t}-\eta E_{t} \pi_{t+1}-(1-\eta) E_{t} \Psi^{1}\left(\pi_{t}\right)\right)+g_{t}\right)\right\} \\
\text { s.t. } i_{t} & \geq-r^{*} \\
u_{t} & =\rho_{u} u_{t-1}+\varepsilon_{u, t} \\
g_{t} & =\rho_{g} g_{t-1}+\varepsilon_{g, t}
\end{aligned}
$$

Note, the value $V\left(\pi_{t-1}, u_{t}, g_{t}\right)$ depends on the state of the shocks and past inflation. The policy functions under discretion are:

$$
\begin{aligned}
& \pi_{t+1}^{D} \equiv \Psi^{1}\left(\pi_{t}, u_{t+1}, g_{t+1}, \mu_{t}^{1}=0, \mu_{t}^{2}=0\right) \\
& y_{t+1}^{D} \equiv \Psi^{2}\left(\pi_{t}, u_{t+1}, g_{t+1}, \mu_{t}^{1}=0, \mu_{t}^{2}=0\right) .
\end{aligned}
$$


For convenience we adopt the short notation:

$$
\begin{aligned}
& \pi_{t+1}^{D} \equiv \Psi^{1}\left(\pi_{t}\right) \\
& y_{t+1}^{D} \equiv \Psi^{2}\left(\pi_{t}\right) .
\end{aligned}
$$

Without (partial) indexation, the value $V$ and policy functions $\left(\Psi^{1}, \Psi^{2}\right)$ do not depend on past inflation.

Rewriting the Lagrangean

$$
\begin{aligned}
& V\left(\pi_{t-1}, u_{t}, g_{t}\right) \\
& =\min _{\left\{\gamma_{t}^{1}, \gamma_{t}^{2}\right\}} \max _{\left\{y_{t}, \pi_{t}, i_{t}\right\}} E_{t} \sum_{t=0}^{\infty}(\beta \eta)^{t}\left\{-\left(\pi_{t}-\zeta \pi_{t-1}\right)^{2}-\lambda y_{t}^{2}+\beta(1-\eta) E_{t} V\left(\pi_{t}, u_{t+1}, g_{t+1}\right)\right. \\
& +\gamma_{t}^{1}\left(\pi_{t}-\frac{1}{1+\beta \zeta}\left(\kappa y_{t}+\beta(1-\eta) E_{t} \Psi^{1}\left(\pi_{t}\right)+\zeta \pi_{t-1}+u_{t}\right)\right)-I_{\eta} \frac{1}{1+\beta \zeta} \mu_{t}^{1} \pi_{t} \\
& \left.+\gamma_{t}^{2}\left(-y_{t}+(1-\eta) E_{t} \Psi^{2}\left(\pi_{t}\right)-\sigma\left(i_{t}-(1-\eta) E_{t} \Psi^{1}\left(\pi_{t}\right)\right)+g_{t}\right)+I_{\eta} \frac{1}{\beta} \mu_{t}^{2}\left(y_{t}+\sigma \pi_{t}\right)\right\} \\
\text { s.t.i } i_{t} & \geq-r^{*} \\
u_{t} & =\rho_{u} u_{t-1}+\varepsilon_{u, t} \\
g_{t} & =\rho_{g} g_{t-1}+\varepsilon_{g, t} \\
\mu_{t}^{1} & =\gamma_{t-1}^{1}, \mu_{0}^{1}=0 \\
\mu_{t}^{2} & =\gamma_{t-1}^{2}, \mu_{0}^{2}=0
\end{aligned}
$$

where $I_{\eta}=0$ if $\eta=0$, and $I_{\eta}=1$ if $\eta \neq 0$. The value function can be written recursively as:

$$
\begin{aligned}
V\left(\pi_{t-1}, u_{t}, g_{t}, \mu_{t}^{1}, \mu_{t}^{2}\right)=\min _{\left\{\gamma_{t}^{1}, \gamma_{t}^{2}\right\}} \max _{\left\{y_{t}, \pi_{t}, i_{t}\right\}} & h\left(\pi_{t-1}, y_{t}, \pi_{t}, i_{t}, \gamma_{t}^{1}, \gamma_{t}^{2}, \mu_{t}^{1}, \mu_{t}^{2}, u_{t}, g_{t}\right) \\
& +\beta \eta E_{t} V\left(\pi_{t}, u_{t+1}, g_{t+1}, \mu_{t+1}^{1}, \mu_{t+1}^{2}\right) \\
& +\beta(1-\eta) E_{t} V\left(\pi_{t}, u_{t+1}, g_{t+1}, 0,0\right)
\end{aligned}
$$


where

$$
\begin{aligned}
& h\left(\pi_{t-1}, y_{t}, \pi_{t}, i_{t}, \gamma_{t}^{1}, \gamma_{t}^{2}, \mu_{t}^{1}, \mu_{t}^{2}, u_{t}, g_{t}\right) \\
& \equiv-\left(\pi_{t}-\zeta \pi_{t-1}\right)^{2}-\lambda y_{t}^{2} \\
& +\gamma_{t}^{1}\left(\pi_{t}-\frac{1}{1+\beta \zeta}\left(\kappa y_{t}+\beta(1-\eta) E_{t} \Psi^{1}\left(\pi_{t}\right)+\zeta \pi_{t-1}+u_{t}\right)\right) \\
& +\gamma_{t}^{2}\left(-y_{t}+(1-\eta) E_{t} \Psi^{2}\left(\pi_{t}\right)-\sigma\left(i_{t}-(1-\eta) E_{t} \Psi^{1}\left(\pi_{t}\right)\right)+g_{t}\right) \\
& -I_{\eta} \frac{1}{1+\beta \zeta} \mu_{t}^{1} \pi_{t}+I_{\eta} \frac{1}{\beta} \mu_{t}^{2}\left(y_{t}+\sigma \pi_{t}\right)
\end{aligned}
$$

\section{A.2 Solution Algorithm}

We use value function iteration to solve the Bellman equation (19). The number of collocation nodes that span the state space $\left(\pi_{t-1}, u_{t}, g_{t}, \mu_{t}^{1}, \mu_{t}^{2}\right) \subset \mathbb{R}^{5}$ is $N=50000$. The solution algorithm is as follows:

1. Make initial guesses for $V, \Psi^{1}$, and $\Psi^{2}$ at the collocation nodes. The solutions of models that do not impose the zero lower bound or do not have indexation can be used as the starting guesses for models with these features.

2. Construct multivariate tensor product spline approximations of $V, \Psi^{1}$, and $\Psi^{2}$. Update $V$ to $V^{\prime}$ by solving the min max problem at each collocation node. In practice, we solve a minimization problem over all state variables subject to nonlinear constraints that correspond to the first order conditions of the maximization problem. Expectations of $V$, $\Psi^{1}$, and $\Psi^{2}$ are approximated using 9 Gauss-Hermite quadrature nodes.

3. Update $\Psi^{1}$ and $\Psi^{2}$ to $\Psi^{1 \prime}$ and $\Psi^{2 \prime}$ using the arguments $\pi_{t}$ and $y_{t}$ of the min max problem, respectively.

4. Repeat steps 2 and 3 until $\max \left[\left|V^{\prime}-V\right|_{\max },\left|\Psi^{1 \prime}-\Psi^{1}\right|_{\max },\left|\Psi^{2 \prime}-\Psi^{2}\right|_{\max }\right]<\epsilon_{t o l}$ where $\epsilon_{\text {tol }}>0$ and $\|_{\max }$ indicates the maximum absolute norm.

The choice of collocation nodes requires some experimentation. We concentrate the nodes where the splines exhibit more curvature. Additionally, the location of the nodes is guided by 
the distribution of values $\left(\pi_{t-1}, u_{t}, g_{t}, \mu_{t}^{1}, \mu_{t}^{2}\right)$ that are encountered in simulations, such that we do not evaluate the functions far outside of the grid of collocation nodes. In the numerical implementation we set $\epsilon_{t o l}=10^{-8}$ and used cubic tensor splines. We examined the robustness of the results with different splines and collocation grids. 